\title{
CSF biomarkers in multiple sclerosis: beyond neuroinflammation
}

\author{
Simona Toscano, Francesco Patti \\ Department "GF Ingrassia", Section of Neurosciences, Multiple Sclerosis Center, University of Catania, Catania 95123, Italy. \\ Correspondence to: Prof. Francesco Patti, Department "GF Ingrassia", Section of Neurosciences, Multiple Sclerosis Center, \\ University of Catania, Catania 95123, Italy.E-mail: patti@unict.it
}

How to cite this article: Toscano S, Patti F. CSF biomarkers in multiple sclerosis: beyond neuroinflammation. Neuroimmuno/ Neuroinflammation 2021;8:14-41. http://dx.doi.org/10.20517/2347-8659.2020.12

Received: 31 Jan 2020 First Decision: 20 May 2020 Revised: 10 Jun 2020

Accepted: 28 Jun 2020 Fisrt online: 21 Aug 2020 Published: 21 Mar 2021

Academic Editor: Roberta Magliozzi Copy Editor: Cai-Hong Wang Production Editor: Jing Yu

\begin{abstract}
For many years, quantifiable biomarkers in neurological diseases have represented a hot topic. In multiple sclerosis (MS), cerebrospinal fluid biomarkers have played a diagnostic role since the introduction of Poser's criteria in 1983, with IgG oligoclonal bands playing a supporting role in an epoch prior to magnetic resonance imaging and a complementary one after the introduction of McDonald criteria in 2001. Nowadays, that supporting role has turned into a main one in substituting for dissemination in time and defining the diagnosis of MS in patients with a first clinical event, according to the 2017 revised McDonald criteria. Possibly kappa free light chains, N-CAM, chitinase 3-like protein 1 and IgM oligoclonal bands, not yet implemented in clinical practice, could similarly gain importance in the near future. Furthermore, the increasing knowledge of molecular mechanisms leading to chronic inflammation has enhanced interest in looking for biomarkers of disease activity, better defining the MS phenotype and patients with highly active disease. Accordingly, myelin proteins, intermediate filaments, metalloproteinases and other molecules involved in the inflammatory cascade, are currently under investigation. Finally, it has long been known that axonal loss occurs from the early phases, leading to a progressive neurological deterioration. Since established criteria to assess treatment failure and transition to progressive forms are still lacking, both treatment response and prognostic biomarkers would be useful to predict MS course, and neurofilaments seem to have this potential. The purpose of this review article was to illustrate biomarkers that have been already validated or require further validation after proving to be useful in exploratory studies and potentially could prove useful in clinical practice in the coming years.
\end{abstract}

Keywords: Multiple sclerosis, biomarkers, cerebrospinal fluid, neurofilaments, oligoclonal bands, disease activity

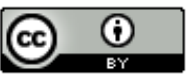

(C) The Author(s) 2021. Open Access This article is licensed under a Creative Commons Attribution 4.0 International License (https://creativecommons.org/licenses/by/4.0/), which permits unrestricted use, sharing, adaptation, distribution and reproduction in any medium or format, for any purpose, even commercially, as long as you give appropriate credit to the original author(s) and the source, provide a link to the Creative Commons license, and indicate if changes were made.

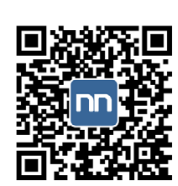




\section{INTRODUCTION}

In the framework of neurological diseases, the need for objective and measurable indicators of the underlying pathological processes is more and more pressing. Therefore, the search for biological markers, or biomarkers, is a continuously expanding field, and a large number of molecules have been explored so far; but only a few have been validated, and even fewer are currently used in clinical practice ${ }^{[1]}$.

Indeed, the assessment of the clinical validity and utility of a biomarker requires a multistage process, which has been proposed as a five-phase procedure going from preclinical exploratory studies (phase 1) to clinical assay development (phase 2), retrospective studies (phase 3), prospective diagnostic accuracy studies (phase 4), and disease burden reduction studies (phase 5$)^{[2]}$. Moreover, the level of evidence relies on the number of supporting studies and patients included while exploring the independence of the results in independent cohorts $^{[3]}$.

With effective therapeutic strategies in neurodegenerative diseases still lacking, biomarkers would allow us to define the start time of degeneration and make an early diagnosis, to monitor the disease course and predict the prognosis, but also to identify potential therapeutic targets ${ }^{[4]}$.

In the context of inflammatory diseases, biomarkers would be useful to specifically define the involved actors of the immune response and potential therapeutic targets, and also to better understand the etiopathogenesis and to monitor disease activity and treatment response ${ }^{[5]}$.

Multiple sclerosis (MS) is a challenging disease, since it is now clear that both inflammatory and degenerative components occur since early phases ${ }^{[6]}$. Although the introduction of the first approved medications for progressive MS (PMS) is a recent achievement ${ }^{[7,8]}$, therapeutic options are actually limited in progressive phases. The majority of currently available disease-modifying drugs (DMDs) target inflammation, and therapeutic efforts are mainly focused on early phases of the disease, with the purpose of influencing long-term evolution ${ }^{[9]}$. It is for this reason that the concept of "no evidence of disease activity" (NEDA) has been introduced as the main therapeutic goal to achieve in patients with MS. Extensively used in clinical trials to define and compare the efficacy of DMDs, the concept of NEDA is still evolving, integrating an increasing number of measures able to define the absence of disease activity. Even though the achievement of this goal is the main one in a clinical real-life setting while monitoring patients under treatment as well, long-term studies are needed to provide evidence of its utility in clinical practice $^{[10]}$. Currently, NEDA-3 is mainly used in clinical trials and considered the aim of therapeutic strategies in clinical practice, consisting in the absence of relapses, magnetic resonance imaging (MRI) activity and sustained disability worsening during follow-up ${ }^{[11]}$. Indeed, the increasingly prominent role of MRI and recent advances in technology have led to the inclusion of the measurement of brain volume loss in NEDA (NEDA-4), which may further evolve with the inclusion of biomarkers (NEDA-5) ${ }^{[12]}$. In this respect, the role of neurofilament light chain (NF-L) as a marker of disease activity, correlating with longterm prognosis seems to be promising ${ }^{[11]}$. The availability of biological markers reflecting such a disease heterogeneity would definitely help us to better understand its complexity and would be an instrument of unquestionable value.

According to the functional classification provided by the FDA-NIH Biomarker Working Group, such molecules can be categorized in susceptibility, diagnostic, monitoring, prognostic, safety and response biomarkers $^{[13]}$ [Table 1].

Susceptibility biomarkers would be useful to detect among asymptomatic individuals those at risk of developing MS, potentially including genetic investigation in first-degree relatives of MS patients ${ }^{[13]}$. 
Table 1. Clinically useful and validated CSF biomarker in MS

\begin{tabular}{|c|c|c|c|}
\hline & Status & Function & Evidence \\
\hline \multirow[t]{2}{*}{$\operatorname{lgG} \mathrm{OCB}$} & $\begin{array}{l}\text { Clinically } \\
\text { useful }\end{array}$ & Diagnostic & $\begin{array}{l}\text { Nearly } 86 \% \text { specificity and more than } 95 \% \text { sensitivity for the diagnosis of } \\
\text { MS }^{[19]} \text {. Implemented in } 2017 \text { McDonald criteria as indicator of DIT }\end{array}$ \\
\hline & & Prognostic for conversion & $\begin{array}{l}\text { Associated with higher risk of conversion in MS when detected in } \mathrm{CIS}^{[28,29]} \\
\text { and } \mathrm{RIS}^{[30-32]}\end{array}$ \\
\hline \multirow[t]{4}{*}{ IgG index } & $\begin{array}{l}\text { Clinically } \\
\text { useful }\end{array}$ & Diagnostic & $\begin{array}{l}\text { Positive values found in } 70-80 \% \text { of MS patients } \\
\text { complementary tool, without replacing CSF } \text {. UG }^{\left[18 \mathrm{CB}^{[41]}\right.}\end{array}$ \\
\hline & & Disease-activity & Associated with MRI activity ${ }^{[45]}$ \\
\hline & & Prognostic for conversion & Associated with higher risk of conversion in MS when detected in $\mathrm{CIS}^{[43]}$ \\
\hline & & Prognostic for progression & Associated with disability progression ${ }^{[44]}$ \\
\hline \multirow[t]{3}{*}{ KFLC } & Validated & Diagnostic & $\begin{array}{l}\text { Useful for the diagnosis of } \mathrm{MS}^{[49,51,53,54,58]} \text {. Increased levels detected in MS } \\
\text { patients with no } \operatorname{lgG} \mathrm{OCB}^{[50,55,62]}\end{array}$ \\
\hline & & Prognostic for conversion & Associated with higher risk of conversion in MS when detected in $\mathrm{CIS}^{[43,60]}$ \\
\hline & & Prognostic for progression & Associated with disability progression ${ }^{[60,64-66]}$ \\
\hline \multirow[t]{4}{*}{$\lg \mathrm{M} O C B$} & Validated & Disease-activity & Associated with aggressive disease course ${ }^{[248,250]}$ \\
\hline & & Prognostic for conversion & $\begin{array}{l}\text { Lipid-specific IgM OCB are associated with higher risk of conversion in CIS } \\
\text { patients }\end{array}$ \\
\hline & & Prognostic for progression & Associated with disability progression and conversion to SPMS ${ }^{[247,248,256]}$ \\
\hline & & Treatment-response & Lipid-specific IgM OCB predict a decreased response to IFN- $\beta^{[256]}$ \\
\hline \multirow[t]{2}{*}{$\mathrm{N}-\mathrm{CAM}$} & Validated & Diagnostic & $\begin{array}{l}\text { Lower levels detected in MS patients and in PPMS compared with RRMS } \\
\text { ones. Considered as an indicator of poor remyelination and repair }{ }^{[180,181]}\end{array}$ \\
\hline & & Disease-activity & $\begin{array}{l}\text { Increased levels detected after relapses, especially under steroid treatment, } \\
\text { and related to clinical remission }\end{array}$ \\
\hline \multirow[t]{4}{*}{$\mathrm{CHISL1}$} & Validated & Diagnostic & Increased levels in MS and NMO patients ${ }^{[185,188,189]}$ \\
\hline & & Prognostic for conversion & Associated with higher risk of conversion to MS in CIS patients ${ }^{[190,192]}$ \\
\hline & & Disease-activity & $\begin{array}{l}\text { Increased levels associated with higher clinical and MRI disease- } \\
\text { activity }^{[190,193]}\end{array}$ \\
\hline & & Treatment-response & $\begin{array}{l}\text { Increased levels in non-responder patients under IFN- } \beta \text { treatment compared } \\
\text { with responders }{ }^{[193]}\end{array}$ \\
\hline \multirow[t]{4}{*}{ NFs } & Validated & Prognostic for conversion & $\begin{array}{l}\text { In RIS increased CSF NF-L are an independent risk factor for the } \\
\text { conversion into CIS and MS, with greater values related to shorter times } \\
\text { of conversion }{ }^{[32]} \text {. Associated with higher risk of conversion to MS in CIS } \\
\text { patients }\end{array}$ \\
\hline & & Disease-activity & $\begin{array}{l}\text { Double NF-L levels in relapsing patients compared with remitting ones }{ }^{[228]} \text {. } \\
\text { CSF NF-L levels correlate with NEDA-3, MRI activity and brain atrophy }{ }^{[11]} \text {. } \\
\text { Serum NF-L in early phases contributed to predict the lesion load and brain } \\
\text { volume loss over a period of } 10 \text { years }{ }^{[238]}\end{array}$ \\
\hline & & Prognostic for progression & $\begin{array}{l}\text { High NF-L concentrations associated with progression in both clinically } \\
\text { stable patients and relapsing ones }{ }^{[226,227]} \text {. In CIS patients with optic neuritis, } \\
\text { CSF NF-L predicted long-term cognitive and physical disability over a follow- } \\
\text { up period ranging between } 9-19 \text { years }{ }^{[235]} \text {. Higher NF-H levels in SPMS } \\
\text { patients }\end{array}$ \\
\hline & & Treatment-response & $\begin{array}{l}\text { NF-L concentrations decreased after } 12-24 \text { months of immunosuppressive } \\
\text { therapy in active progressive MS patients }{ }^{[239]} \text {, after switching from first-line } \\
\text { therapies to fingolimod }{ }^{[240]} \text { and after } 12 \text { months of } N T Z^{[241,242]}\end{array}$ \\
\hline MBP & Validated & Disease-activity & $\begin{array}{l}\text { Higher values detected in active RRMS compared with stable patients } \\
\text { and progressive MS. Increased levels in MS are temporally related to } \\
\text { relapses and detectable up to } 5-6 \text { weeks after, with greater values in } \\
\text { polysymptomatic and severe exacerbations }{ }^{[158,159,166-168]} \text {. Reduced levels after } \\
\text { steroid treatment }{ }^{[168,169]}\end{array}$ \\
\hline \multirow[t]{2}{*}{ GFAP } & Validated & Prognostic for progression & $\begin{array}{l}\text { Elevated levels in MS compared with controls }{ }^{[265-267]} \text {, with higher values in } \\
\text { patients with EDSS greater than } 6.5^{[266]} \text {. Associated with greater EDSS score, } \\
\text { longer disease duration and progressive course }{ }^{[268]} \text {. Increased levels of GFAP } \\
\text { in MS predictive for the disability achieved } 8-10 \text { years later }\end{array}$ \\
\hline & & Disease-activity & $\begin{array}{l}\text { Associated with MRI parameters as infratentorial chronic lesion load and the } \\
\text { intensity of Gd+ in both CIS and RRMS patients }\end{array}$ \\
\hline \multirow[t]{2}{*}{ MMP-9 } & Validated & Disease-activity & $\begin{array}{l}\text { Elevated values during clinical relapses, related to a greater number of MRI } \\
\text { Gd+ lesions }{ }^{[144]} \text {. Higher values in MS compared with controls and in RRMS } \\
\text { compared with PPMS }{ }^{[148]}\end{array}$ \\
\hline & & Treatment-response & Decreased levels after treatment with IFN- $\beta^{[152-154]}$ and NTZ $Z^{[155]}$ \\
\hline \multirow[t]{4}{*}{ CXCL13 } & Validated & Diagnostic & $\begin{array}{l}\text { Higher levels in MS patients compared with controls, though low } \\
\text { specificity }\end{array}$ \\
\hline & & Prognostic for conversion & Associated with higher risk of conversion to MS in CIS patients ${ }^{[130]}$ \\
\hline & & Disease-activity & $\begin{array}{l}\text { Associated with clinical and radiological activity }{ }^{[126,127]} \text {. Decreased levels after } \\
\text { steroid treatment }^{[127]}\end{array}$ \\
\hline & & Treatment-response & Decreased levels after treatment with NTZ ${ }^{[127,132]}$, RTX $^{[129,131]}$ \\
\hline
\end{tabular}




\begin{tabular}{|c|c|c|c|}
\hline \multirow[t]{2}{*}{ OPN } & \multirow[t]{2}{*}{ Validated } & Diagnostic & Significantly greater levels in MS patients compared with controls ${ }^{[102,107,108,10]}$ \\
\hline & & Disease-activity & $\begin{array}{l}\text { In RRMS patients, higher levels detected in active disease compared with } \\
\text { stable disease and during relapses compared with remission phases }{ }^{[100-103]}\end{array}$ \\
\hline $\begin{array}{l}\text { NO } \\
\text { metabolites }\end{array}$ & Validated & Disease-activity & $\begin{array}{l}\text { Increased levels in body fluids of MS patients, particularly RRMS compare } \\
\text { with SPMS. Higher values detected during relapses }{ }^{[7,90]}\end{array}$ \\
\hline \multirow[t]{2}{*}{$\begin{array}{l}\text { MRZ } \\
\text { reaction }\end{array}$} & \multirow[t]{2}{*}{ Validated } & Diagnostic & $\begin{array}{l}\text { A humoral response against at least } 2 \text { of } 3 \text { viruses is detected in } 78 \% \text { of } \\
\text { patients with MS with high specificity }{ }^{[73]}\end{array}$ \\
\hline & & Prognostic for conversion & Associated with higher risk of conversion in MS when detected in $\mathrm{CIS}^{[69,70]}$ \\
\hline
\end{tabular}

MS: multiple sclerosis; CIS: clinically isolated syndrome; RIS: radiologically isolated syndrome; MRI: magnetic resonance imaging; OCB: oligoclonal bands; RRMS: relapsing-remitting multiple sclerosis; SPMS: secondary progressive multiple sclerosis; NMO: neuromyelitis optica; NEDA: no evidence of disease-activity; N-CAM: neuronal cell adhesion molecule; CHI3L1: chitinase-3-like-1; MBP: myelin basic protein; GFAP: glial fibrillary acidic protein; Gd+: gadolinium-enhancing; MMP-9: matrix metalloproteinase-9; CXCL13: C-X-C motif ligand 13; NFs: neurofilaments; NF-L: light chains of neurofilaments; NF-H: heavy chains of neurofilaments; OPN: osteopontin; NO: nitric oxid; MRZ: measles-rubella-varicella; NTZ: natalizumab; RTX: rituximab

Diagnostic biomarkers should be able to confirm the diagnosis of MS, improving diagnostic accuracy when applied together with clinical and MRI criteria. Thus, they can allow clinicians to exclude other possible differential diagnoses, including different autoimmune disorders and other neurological diseases. They should also ideally detect patients with clinically isolated syndrome (CIS) and radiologically isolated syndrome (RIS) and distinguish between different subtypes of the disease ${ }^{[5,13]}$.

Monitoring biomarkers play a relevant role in MS, allowing neurologists to serially assess the status of the disease $^{[13]}$. Particularly, disease activity biomarkers may crucially affect therapeutic decisions by detecting high disease activity and rapid disability worsening in early phases of $\mathrm{MS}^{[9,14]}$. Correlating with clinical and radiological activity, they may aid in identifying aggressive forms of MS and also provide an indirect assessment of low therapeutic response in patients under DMDs ${ }^{[1]}$.

The definition of prognostic biomarkers as a separate class is slightly more controversial, since a prognostic impact is recognized in other categories of biomarkers ${ }^{[1]}$. Indeed, those markers able to predict either the risk of relapses or progression or both would belong to this group ${ }^{[13]}$. However, this term is usually attributed to those molecules reflecting axonal damage, astrocyte activation and remyelination, prevailing in progressive phases of disease ${ }^{[4]}$. They would also be important in identifying transitional progressive forms of MS, since reliable indicators are not available ${ }^{[9]}$. Alongside these, many studies have considered those molecules that are predictive of conversion to clinically definite MS when detected in patients with CIS as being "prognostic". To distinguish these "prognostic for conversion" biomarkers from the aforementioned "prognostic for progression" ones, their role in this review will be discussed as belonging to the diagnostic category for conceptual similarity.

Finally, the monitoring of treatment response in terms of both efficacy and safety may be very important in personalizing therapies and planning switches whenever appropriate ${ }^{[5]}$ and may be of benefit in the use of pharmacodynamic/response and safety biomarkers ${ }^{[13]}$.

However, boundaries are blurred and some markers may exhibit more than one function. Moreover, to be validated, exploratory molecules have to be reproducible among independent studies, and only easily detectable and cost-effective ones truly impacting the diagnostic therapeutic processes would be used in clinical practice ${ }^{[5]}$.

For both anatomic and physiological reasons, cerebrospinal fluid (CSF) represents the main source of potential biomarkers for MS among body fluids ${ }^{[4]}$. Indeed, its composition may reflect the impairment of brain metabolism, the breakdown of the blood-brain barrier (BBB) and many ongoing processes occurring in the central nervous system (CNS) with a consequent production of catabolites ${ }^{[15]}$. However, requiring less invasiveness and due to blood continuity with CSF, serum samples are being increasingly used and explored as a source of biomarkers ${ }^{[1]}$. 
Considering the extensive number of molecules that are currently under investigation and detected in body fluids, this review will focus on CSF biomarkers that are currently used in clinical practice, those that have not been clinically implemented although validated and those requiring further validation after proving to be useful in small exploratory single-site studies. Since some molecules may potentially fall in more than one category according to a functional classification, they will be classified according to their main recognized role.

\section{DIAGNOSTIC BIOMARKERS}

\section{IgG oligoclonal bands}

CSF IgG oligoclonal bands (IgG OCB) are detected in almost $90 \%$ of patients with MS and in nearly $70 \%$ of patients with $\mathrm{CIS}^{[16]}$. It does not seem that OCB-negative MS shows different characteristics, even though a different immunogenetic phenotype of HLA-DRB1 has been identified in some studies ${ }^{[17]}$. Among several techniques, isoelectric focusing followed by immunofixation in parallel CSF and serum samples is mainly used for their detection due to a high sensitivity ${ }^{[18,19]}$. Of all possible patterns, type 2 is detected when at least two bands of IgG are present in CSF but not in serum, which is suggestive of intrathecal IgG synthesis and thus of an inflammatory disease of the $\mathrm{CNS}^{[18]}$.

As a qualitative assessment, CSF IgG OCB detection is actually considered a more reliable test than any quantitative assessments of intrathecal synthesis ${ }^{[20]}$. With nearly $86 \%$ specificity and more than $95 \%$ sensitivity, CSF IgG OCB do not represent a pathognomonic finding of MS, but they may strongly support the diagnosis of MS when other causes of CNS inflammation have been ruled out ${ }^{[19]}$.

In 2017, the latest revised McDonald criteria gave great significance to CSF OCB as a substitute for dissemination in time ${ }^{[20]}$, increasing sensitivity in the diagnosis of relapsing-remitting MS (RRMS) in patients with a first clinical event ${ }^{[21]}$. CSF IgG OCB already had a role as a diagnostic biomarker before, first in Poser's criteria (1983) to define "laboratory supported" definite and probable MS diagnosis ${ }^{[2]}$. Years later, both the McDonald et al. ${ }^{[23]}$ and Polman et al ${ }^{[24]}$ criteria considered the presence of CSF IgG OCB as sufficient to provide the evidence of dissemination in space (DIS), together with the detection of at least two MRI lesions consistent with MS. Although not being included in 2010 revised criteria ${ }^{[25]}$, CSF analysis with IgG OCB detection still represents a common step of the diagnostic program, particularly because it may allow us to exclude other diagnoses adding a different type of information compared with MRI, which may be unable to allow the distinction between MS and mimics at early stages ${ }^{[26]}$. Moreover, it has been argued that the presence of CSF OCB may increase the specificity of those criteria when considered together with DIS ${ }^{[27]}$.

Concerning the diagnosis of primary progressive MS (PPMS), the presence of CSF OCB is one of the required criteria ${ }^{[20]}$ and its role has been confirmed over time in the consecutive revisions after Poser's criteria ${ }^{[23-25]}$. In addition to a diagnostic role, CSF IgG OCB also has a prognostic role for conversion to MS, since their identification in patients with CIS increases the risk to convert into clinically definite MS with a negative predictive value of $88 \%{ }^{[28]}$. In a prospective study conducted by Tintoré and coworkers in 572 patients with CIS, the detection of CSF IgG OCB almost doubled the risk of a second relapse, regardless of baseline MRI, without affecting disability outcomes during a follow-up of 50 months ${ }^{[29]}$.

Despite recognizing the presence of CSF IgG OCB as one of the factors predicting an increased risk to develop MS in patients with RIS ${ }^{[30]}$, specific criteria have not been established in the 2017 latest revision ${ }^{[20]}$. Results from a recent study showed that the presence of CSF OCB in children with RIS increased the risk to develop pediatric MS and improved specificity of MRI criteria in these patients ${ }^{[31]}$. In another study conducted in 75 patients with RIS, CSF OCB also proved to be an independent risk factor for the conversion to CIS and MS and were associated with shorter times of conversion ${ }^{[32]}$. 
It has been suggested that the presence of CSF OCB, indicative of intrathecal synthesis, may both directly and indirectly perpetuate the inflammatory damage through the chronic stimulation of microglia via immunoglobulin and immunocomplexes. Occurring even once acute perivascular inflammation has stopped, such an activation facilitates further and mutual activation of both microglia and astrocytes. As a result, antibody-mediated inflammation promotes a microenvironment of chronic inflammatory damage and neurodegeneration ${ }^{[33]}$. From this perspective, the administration of a drug able to affect local humoral production would be further useful. However, among the currently available drugs, only natalizumab (NTZ) and cladribine proved to affect intrathecal Ig synthesis, ultimately leading to CSF OCB disappearance in some cases ${ }^{[34-37]}$. Nevertheless, the presence of CSF OCB does not seem to be associated with an aggressive disease course or a faster disease progression in $\mathrm{MS}^{[17,38]}$.

IgG OCB represent a validated and clinically implemented biomarker for both the diagnosis of MS and the detection of CIS converters. Its validity relies on numerous confirmatory studies conducted in more than 200 patients, thus providing a strong level of evidence ${ }^{[3]}$.

\section{IgG index}

The ratio between IgG quotient and albumin quotient, known as the Link Index ${ }^{[39]}$, is largely used to assess a quantitative evaluation of intrathecal synthesis, enough to be considered an alternative to the detection of CSF OCB in previous MS diagnostic criteria ${ }^{[22-24]}$. However, the latest revision of McDonald criteria clearly states that the identification of CSF IgG OCB is superior to any quantitative assessments, whose results have to be cautiously considered when isolated or conflicting with the aforementioned tool ${ }^{[20]}$. In addition, it has been clearly defined in two different consensus statements that $\operatorname{IgG}$ index and other quantitative assessments are just complementary tests, less sensitive than qualitative detection of $\operatorname{CSF~OCB~}^{[18,19]}$. A value greater than 0.70 is universally considered suggestive of pathological intrathecal synthesis for IgG index, with abnormal values detected respectively in $70 \%-80 \%$ of patients with clinically definite $\mathrm{MS}^{[18]}$. With a cut-off value of 0.7 , a positive predictive value by $60 \%$ for the diagnosis of demyelinating CNS disease has been found ${ }^{[40]}$. Considering that a correlation exists between $\operatorname{IgG}$ index and positive predictive value for MS, increasing IgG index values correlate with a greater probability of MS diagnosis ${ }^{[40]}$. Nonetheless, abnormal values are rarely detected in MS patients with no CSF $\mathrm{OCB}^{[41]}$.

Nephelometry is the most used technique to measure albumin in CSF and serum as well, to provide a quotient that is a reliable measure of blood-CSF barrier function, especially when age-related ${ }^{[18,19]}$. This is crucial, since the increased concentration of a substance in CSF can be the result of either intrathecal synthesis or increased permeability of the blood-CSF barrier. Moreover, interindividual variability in serum IgG concentrations is similarly reduced by using a CSF/serum IgG quotient ${ }^{[18]}$.

Applying different mathematical models, several indices have been derived ${ }^{[42]}$, including Tourtellotte's, Reiber's, Link's and intrathecal IgG fraction. Actually, although the IgG index is the most commonly used quantitative measure of intrathecal synthesis in clinical practice, other indices using hyperbolic mathematical functions, such as Reiber's index, are considered more accurate, resulting in few false positives $^{[18,19]}$. Senel and coworkers found $43 \%$ sensitivity and $64 \%$ specificity for IgG index regarding conversion of CIS to clinically definite MS, with a positive predictive value of $53 \%$ and a negative one of $54 \%{ }^{[43]}$.

As a prognostic biomarker, a very high IgG index has been related to a major disability progression with greater values in secondary progressive MS (SPMS) compared with PPMS and RRMS patients in a study conducted by Izquierdo and coworkers ${ }^{[44]}$.

Finally, a recent retrospective study involving 149 patients with CIS and MS investigated a possible 
association between CSF parameters and MRI activity. IgG index was highly correlated with the detection of new cerebral lesions on MRI scan and proved to be an independent predictor of future MRI activity ${ }^{[45]}$.

Currently, IgG index is clinically implemented as additional evidence of CNS local humoral response, with the advantage of being based on easily achievable information from a simple CSF analysis ${ }^{[46]}$. Thus, it is useful in supporting the diagnosis of MS and could represent a complementary screening test in patients suspected of MS, without replacing the diagnostic value of $\mathrm{CSF} \mathrm{OCB}^{[41]}$.

\section{Kappa free light chains and kappa index}

CSF kappa free light chains (KFLC) result from intrathecal humoral activity of plasma cells. Being normal constituents of human Ig structure together with lambda light chains, they tend to accumulate together with Ig in inflammatory disease of $\mathrm{CNS}^{[47]}$ and can be detected by ELISA, Western blotting ${ }^{[48]}$ or nephelometry ${ }^{[49-51]}$. Several studies reported an increased concentration of free light chains in CSF of patients with $\mathrm{MS}^{[49,51]}$. As for IgG index, the use of a ratio between KFLC CSF/serum quotient and albumin quotient has been considered by the majority as the best method to represent intrathecal FLC synthesis ${ }^{[47,51]}$, with some exceptions ${ }^{[49,52]}$. Conversely, lambda FLC Index did not prove to have comparable values of sensitivity and specificity, and it is currently not considered a potential diagnostic biomarker for $\mathrm{MS}^{[49,53]}$.

KFLC index has been explored as a diagnostic biomarker, despite the lack of an unequivocal cut-off value currently causes some difficulties in comparing results from several studies [Table 2]. As an indicator of intrathecal synthesis, KFLC index correlates well with $\operatorname{IgG}$ index ${ }^{[54]}$, using a cut-off value of 5, although showing greater sensitivity (more than $96 \% v$ s. nearly 50\%) for CSF IgG OCB identification and MS diagnosis and according to higher negative predictive values, with comparable specificity.

Although different thresholds have been used in several studies, ranging from $4.25^{[55]}$ to $12.3^{[53]}$, KFLC index extensively proved to have a higher sensitivity and a lower specificity with a similar diagnostic accuracy compared with IgG OCB in discriminating MS and controls ${ }^{[53,55-59]}$. In a recent study by Gaetani and coworkers, KFLC index distinguished precisely as did IgG OCB between MS and non-inflammatory diseases using a cut-off value of $7.83^{[56]}$. It has been suggested that a higher cut-off value (10.6) could be useful to differentiate MS from other inflammatory diseases by increasing specificity and to predict conversion in CIS with greater accuracy as compared with $\mathrm{OCB}^{[56]}$. Similarly, high levels of CSF KFLC have also been demonstrated in CIS patients, showing a correlation with the risk of conversion to clinically definite MS within 2 years ${ }^{[43,60]}$. Moreover, unlike KFLC index threshold, a cut-off value for intrathecal KFLC synthesis has proved to be more reproducible ${ }^{[58,61,62]}$.

Noteworthy, KFLC index proved to be increased in MS patients with no evidence of IgG OCB, amounting to almost $5 \%$ of cases ${ }^{[50,55,62]}$, showing a greater sensitivity but a less specificity by using a threshold of 5.9 . In a recent study by Ferraro and coworkers, a KFLC index $\geq 5.8$ was detected in $25 \%$ of OCB-negative MS patients and in $98 \%$ of OCB-positive ones ${ }^{[63]}$.

It has been hypothesized that KFLC index may replace IgG index as a first-line test, but some disagreement remains about the need to determine both KFLC index and IgG OCB in patients with suspected $\mathrm{MS}^{[63]}$ or to use them sequentially ${ }^{[5]}$. Probably, the higher sensitivity of KFLC index compared with IgG OCB would allow clinicians to screen patients in a shorter time, with lower costs and the advantage of a quantitative assessment ${ }^{[49,58]}$, restricting the use of IgG OCB to patients with positive KFLC index. Such a diagnostic route would allow clinicians to reduce false positive results when faced with an inflammatory disease of the CNS. Showing a comparable or higher specificity ${ }^{[50,54]}$, IgG index could still have a role as a screening test complementary to KFLC index for the detection of intrathecal Ig synthesis. However, KFLC index currently shows an intermediate level of evidence as a diagnostic biomarker, requiring other confirmatory studies in larger cohorts $^{[3]}$. 
Table 2. Different cut-off values for kappa index and characteristics of study cohorts

\begin{tabular}{|c|c|c|c|c|c|c|c|}
\hline & $\begin{array}{c}\text { Study cohort } \\
\text { (number of analyzed } \\
\text { paired serum and } \\
\text { CSF samples) } \\
\end{array}$ & $\begin{array}{c}\text { True } \\
\text { positives }\end{array}$ & $\begin{array}{c}\text { True } \\
\text { negatives }\end{array}$ & Cut-off & Sensitivity & Specificity & $\begin{array}{l}\text { McDonald's } \\
\text { diagnostic } \\
\text { criteria }\end{array}$ \\
\hline Crespi et $a{ }^{[54]}$ & 385 & MS (127) & $\begin{array}{l}\text { Other neurological diseases: } \\
\text { IND (117) } \\
\text { NIND (141) }\end{array}$ & $\geq 5$ & 96 & 78 & 2017 \\
\hline Gaetani et al. ${ }^{[56]}$ & 170 & $\begin{array}{l}\text { RIS, CIS, } \\
\text { MS (64) }\end{array}$ & $\begin{array}{l}\text { Other neurological diseases } \\
\text { (106): } \\
\text { IND (24) } \\
\text { NIND (82) }\end{array}$ & $\geq 7.83$ & 89 & 81 & 2010 \\
\hline Gurtner et $a / .{ }^{[57]}$ & 320 & $\begin{array}{l}\text { RIS, CIS, } \\
\text { MS (67) }\end{array}$ & $\begin{array}{l}\text { Other neurological diseases } \\
\text { ( } 258) \text { : } \\
\text { autoimmune (53), } \\
\text { NIND ( } 50) \text {, } \\
\text { IND (38), } \\
\text { degenerative (28), peripheral } \\
\text { neuropathy (24), } \\
\text { infection (13), } \\
\text { cancer (11), } \\
\text { neuromyelitis optica (10), } \\
\text { others (31) }\end{array}$ & $\geq 10.5$ & 87 & 76 & 2010 \\
\hline Leurs et al. ${ }^{[59]}$ & $\begin{array}{l}745 \text { (from } 18 \\
\text { centers) }\end{array}$ & $\begin{array}{l}\text { CIS, MS } \\
(526)\end{array}$ & $\begin{array}{l}\text { Controls (219): } \\
\text { IND (67) } \\
\text { NIND (76) } \\
\text { Symptomatic controls (49) } \\
\text { Healthy controls (27) }\end{array}$ & $\geq 6.6$ & $\begin{array}{l}88 \\
93 \text { (MS } \\
\text { and } \\
\text { controls) }\end{array}$ & $\begin{array}{l}83 \\
83 \text { (MS } \\
\text { and } \\
\text { controls) }\end{array}$ & $\begin{array}{l}2010(84 \%) \\
2005(16 \%)\end{array}$ \\
\hline Pieri et al. ${ }^{[53]}$ & 176 & MS (71) & $\begin{array}{l}\text { Other neurological diseases: } \\
\text { IND (33) } \\
\text { NIND (72) }\end{array}$ & $\geq 12.3$ & 93 & 100 & 2010 \\
\hline Presslauer et al. ${ }^{[58]}$ & $\begin{array}{l}438 \text { (from } 4 \\
\text { centers) }\end{array}$ & $\begin{array}{l}\text { CIS/MS } \\
(70)\end{array}$ & $\begin{array}{l}\text { Other neurological diseases } \\
\text { ( } 368) \text {, including meningitis/ } \\
\text { encephalitis (41) } \\
\text { Guillain-Barré (15) } \\
\text { Neuroborreliosis (15) } \\
\text { CIDP (7) }\end{array}$ & $\geq 5.9$ & 96 & 86 & 2010 \\
\hline Puthenparampil et al. ${ }^{[55]}$ & 137 & MS (70) & $\begin{array}{l}\text { Healthy controls (symtpomatic } \\
\text { despite no neurological and } \\
\text { systemic disorders) (37) }\end{array}$ & $\geq 4.25$ & 94 & 100 & 2017 \\
\hline
\end{tabular}

MS: multiple sclerosis; CIS: clinically isolated syndrome; RIS: radiologically isolated syndrome; IND: inflammatory neurological diseases; NIND: non-inflammatory neurological diseases; CIDP: chronic inflammatory demyelinating polyneuropathy

It has also been pointed out that higher values of KFLC index are associated with greater disability ${ }^{[60,64-66]}$, even though previous authors did not go in the same direction but hypothesizing a prognostic role for this marker ${ }^{[61,67]}$.

\section{Measles-rubella-varicella-zoster reaction}

In the 1994 consensus report about CSF analysis in the diagnosis of MS, the detection of intrathecal Ig synthesis against neurotrophic viruses, such as measles, rubella and varicella-zoster, was considered a complementary diagnostic test for $\mathrm{MS}^{[18]}$. Such kind of local humoral response, called measles-rubellavaricella-zoster (MRZ) reaction (MRZR), has been reported in up to $94 \%$ of patients with MS if at least one intrathecal virus-specific response is detected ${ }^{[68]}$, with anti-measles response as the most frequent one ${ }^{[69-71]}$. However, MRZR is usually considered positive if a humoral response against at least 2 of 3 viruses is reported, with a commonly used cut-off value of 1.5 for antibody index ${ }^{[72,73]}$. The reason for this local humoral response, which occurs without active replication of the virus ${ }^{[74]}$, has not been entirely clarified ${ }^{[75]}$. An involvement of $\mathrm{T}$ lymphocytes promoting the differentiation of memory B cells into antibody secreting ones has been suggested ${ }^{[70]}$.

High specificity of up to $97 \%$ for MRZR was also reported by Jarius and coworkers, who found a positive reaction in $78 \%$ of patients with MS compared to $3 \%$ of controls. Moreover, MRZR has proved to be able to 
distinguish between MS and other diseases, such as neuromyelitis optica (NMO $)^{[73]}$, anti-MOG associated encephalomyelitis ${ }^{[73]}$, and primary CNS lymphoma ${ }^{[72]}$.

In a prospective 2-year study involving 89 patients with CIS, MRZ reaction was associated with a greater risk to convert to clinically definite MS, showing a greater positive predictive value (70\%) than OCB (64\%) and MRI $(64 \%)^{[70]}$. In patients with acute optic neuritis with positive MRZR and MRI, conversion to clinically definite MS occurred in $86 \%$ of them after 4 years, with a prevalence of $73 \%$ for MRZR in those who converted ${ }^{[69]}$. Thus, MRZR can further support the diagnosis at onset and assist in discrimination between MS and other clinically similar inflammatory diseases, representing a complementary diagnostic biomarker with an intermediate level of evidence ${ }^{[3,74]}$. Nevertheless, further studies in additional cohorts are required $^{[3]}$.

\section{DISEASE ACTIVITY BIOMARKERS}

\section{Nitric oxide metabolites}

Due to the role of oxidative stress in MS pathogenesis, nitrate and nitrite have been investigated as disease activity biomarkers ${ }^{[76]}$. Indeed inflammatory processes produce, as a result of the activation of immune cells, reactive oxygen species, including nitrogen-based oxidants ${ }^{[76]}$. Moreover, Nitric oxide (NO) seems to have much more roles than being a blood flow controller and a synaptic transmitter, regulating the permeability of the BBB, exerting immunomodulatory properties and mediating axonal damage and demyelination ${ }^{[77]}$.

Increased levels of nitrate and nitrite have been identified in body fluids of MS patients in several studies. Particularly, many studies have reported greater concentrations of these molecules in $\operatorname{CSF}^{[78-80]}$, serum ${ }^{[8,82]}$ and urine ${ }^{[83]}$ of MS patients compared with controls. Accordingly, the inducible form of nitric oxide synthase has been detected in CSF of MS patients, while not in healthy controls ${ }^{[84]}$, and its mRNA has been found in cerebral tissue of MS patients ${ }^{[77]}$. Interestingly, interferon-beta (IFN- $\beta$ ) has proved to exert a remarkable inhibition of inducible NO synthase expression in astrocytes ${ }^{[85]}$.

Meanwhile, it is still controversial whether the concentration of NO metabolites is significantly different in RRMS compared with PMS. Indeed, some studies found higher CSF and serum levels of NO metabolites in RRMS compared with SPMS ${ }^{[86,87]}$, while others did not detect any differences ${ }^{[8,88]}$.

Speculating a role as a disease activity biomarker, the association between NO metabolites and the occurrence of relapses in RRMS patients has been explored, and several studies have confirmed this hypothesis ${ }^{[78,89-91]}$, but longitudinal and multicenter studies are needed.

In a study by Yamashita et al. ${ }^{[78]}$, significantly higher nitrite and nitrate levels were detected among patients in relapse compared with those in remission and patients treated with steroid in the previous 1-2 months. Acar et al. ${ }^{[90]}$ found higher nitrate and nitrite concentrations in relapsing patients than in remitting ones, with the latter ones still showing greater values than controls. Accordingly, NO metabolites predicted disease activity with $71 \%$ specificity and $66 \%$ sensitivity. In contrast, few studies reported evidence of an association between NO metabolites and MRI findings ${ }^{[00,92]}$, as well as between the development of disability and EDSS progression ${ }^{[92]}$.

\section{Osteopontin}

Osteopontin $(\mathrm{OPN})$ is a sialoprotein, whose role in bone remodeling has long been known ${ }^{[93]}$. Beyond this, it is closely linked to the immune system, since it mediates chemotaxis, cell adhesion and signaling, and it also promotes cytokine and interleukin (IL) function, inducing IL-12 and inhibiting IL-10 among others. In its soluble form, indeed, it is secreted by and also interacts with macrophages and activated leukocytes, reduces the inducible form of NO synthase, promoting inflammation. In its intracellular 
form, it is expressed by dendritic cells and promotes Th17 and Treg differentiation ${ }^{[94]}$. Moreover, it is thought to mediate the upregulation of Th1 and Th17 cytokines, mainly IFN- $\gamma$ and IL- $17^{[95]}$, and the inhibition of pro-apoptotic proteins, favoring $\mathrm{T}$ cell survival ${ }^{[96]}$. It has been suggested that a specific subset of Th1 cells, particularly arising in CSF during relapses, produces OPN, high levels of IFN- $\gamma$ and matrix metalloproteinase-9 (MMP-9) after polyclonal stimulation, playing a pathogenetic role ${ }^{[97]}$.

In experimental models of relapsing-remitting experimental autoimmune encephalomyelitis (EAE), OPN expression was constantly evidenced in microglia next to periventricular lesions and in neurons limited to the relapse phase, which increased in mice with greater disease severity ${ }^{[98]}$. Moreover, when recombinant OPN was given to mice, severe relapses occurred after 1-3 days. Conversely, knockout mice for OPN seemed to be protected from the development of severe $\mathrm{EAE}^{[96]}$.

Accordingly, immunohistochemistry analysis of MS brain lesions in humans identified marked OPN expression immediately near the lesions, in vascular endothelial cells, microglia and astrocytes, which was greater in more active lesions ${ }^{[98,99]}$.

High levels of OPN have been found in plasma of RRMS patients, with greater concentrations in patients with active disease compared with those without exacerbations ${ }^{[100-103]}$ and during relapses compared with remissions ${ }^{[102,104,105]}$. Similar results were found in other studies ${ }^{[96,101,106]}$, with significantly higher CSF and serum OPN levels in MS patients compared with controls ${ }^{[102,107-110]}$. A positive correlation between IL-17 and both OPN and IL-23 concentrations has also been found ${ }^{[106]}$. Moreover, CSF concentrations of OPN in MS patients, re-evaluated 5 years after sampling, proved to be not only elevated but also related to the occurence of relapses and to clinical severity ${ }^{[11]}$. It has been supposed that the increase in OPN during relapses has an inverse correlation with the concentration of serum extracellular proteasome, with marked effects on chemotaxis ${ }^{[112]}$. However, other studies did not find a clear association between OPN levels and disease activity ${ }^{[107,113]}$.

According to some studies, SPMS patients exhibited elevated OPN values as well compared with controls ${ }^{[102,107]}$, while a significant difference was not reported by other studies ${ }^{[104]}$. In a recent meta-analysis by Agah and coworkers, all MS patient subtypes showed higher OPN levels compared with controls, except for $\mathrm{CIS}^{[101]}$. However, greater concentrations were found in RRMS patients compared with all other groups and in those with exacerbations compared with patients with stable disease.

IFN- $\beta$ proved to downregulate OPN and IL-17 in MS patients and to decrease the incidence of EAE and the amount of Th1 and Th17 cells in mice ${ }^{[114,115]}$. Indeed, RRMS patients treated with IFN- $\beta$ showed OPN at similar levels compared to untreated patients in remission phase ${ }^{[96]}$. Glatiramer acetate and NTZ lead to the decrease of plasma OPN levels as well ${ }^{[107,116]}$. Several polymorphisms of the OPN gene have been investigated to find an association with disease course or activity ${ }^{[117-120]}$. A few have been correlated with the level of disability ${ }^{[118]}$, with disease course and risk for conversion to SPMS ${ }^{[119,120]}$, and with susceptibility to MS development and relapse rate ${ }^{[121]}$.

Additional studies are needed to confirm the role of OPN as a useful disease activity biomarker.

\section{C-X-C motif ligand 13}

C-X-C motif ligand 13 (CXCL13), also known as B cell attracting chemokine (BCA-1), is a protein favoring the chemotaxis of mature B lymphocytes by interaction with its receptor CXCR5. This receptor is also expressed by CD4+ T follicular helper cells, CD4+ Th1 7 cells, activated Treg cells and a subgroup of CD8+ T cells ${ }^{[122]}$. 
Together with other lymphoid chemokines, it favors the organization of germinal centers in lymphoid follicles, including meningeal tertiary lymphoid organs in the $\mathrm{CNS}^{[122]}$. Indeed, CXCL13 has been found to be overexpressed in active MS lesions and in intrameningeal B-cell follicles of chronic white matter lesions, sustaining humoral autoimmunity and disease activity ${ }^{[122,123]}$. Not coincidentally, mice lacking CXCL13 develop milder forms of disease ${ }^{[124]}$, and its expression correlates with intrathecal Ig syntesis ${ }^{[125]}$.

In a recent meta-analysis conducted on 226 studies about the role of several cytokines in patients with MS, CSF CXCL13 levels proved to differentiate well between patients with MS and controls and to decrease after DMDs ${ }^{[126,127]}$. Accordingly, in a study by Khademi and coworkers, CSF CXCL13 was found to be significantly higher in infectious neurological diseases and MS. The latter group showed significantly higher values than CIS and other controls ${ }^{[128]}$. However, its lack of high specificity was confirmed by overexpression of CXCL13 in the CNS in other diseases, such as neuroborreliosis and primary CNS lymphoma ${ }^{[129]}$. Next to its diagnostic role, it also proved to be higher in CIS converting to clinically definite MS $^{[130]}$ and to correlate with both clinical and radiological disease activity ${ }^{[127,128]}$. Currently, its role as predictive for CIS conversion has an intermediate level of evidence, needing replication in additional cohorts ${ }^{[3]}$.

Elevated levels of CSF CXCL13 also seem to decrease after B-cell depleting treatment such as rituximab $^{[129,131]}$, after methylprednisolone ${ }^{[127]}$ and NTZ ${ }^{[127,132]}$. High CSF CXCL13 levels also correlated with low expression of immunoregulatory IL-10 and TGF- $\beta 1^{[127]}$. On the basis of this evidence, CSF CXCL13 has been mainly suggested as a disease activity and treatment response biomarker.

\section{MMP-9}

MMPs are zinc-endopeptidases, able to catalyze the cleavage of many substrates in several physiological and physiopathological processes. Indeed, MMPs play a role in tissue remodeling, angiogenesis and cell migration, but also in inflammation, wound healing and malignancies ${ }^{[133]}$. During inflammation, many molecules are able to activate MMPs, including reactive oxygen species and both TNF- $\alpha$ and IL-17 via NF- $\mathrm{B}^{[134,135]}$. MMPs, in turn, are able to activate cytokines, adhesion molecules, receptors and microglia ${ }^{[136,137]}$. Moreover, MMPs may determine BBB dysfunction by proteolyzing capillary basement membrane and tight junction proteins between endothelial cells ${ }^{[133,138]}$.

MMPs seem to be involved in several neurological diseases, such as MS, Alzheimer's disease, Parkinson's disease, cancer and cerebrovascular diseases ${ }^{[133]}$. In EAE, elevated levels of several MMPs have been found, considered responsible for major severity of the disease ${ }^{[133,139,140]}$. It has been supposed that MMPs may act in MS through the digestion of myelin basic protein (MBP) as well, besides favoring leukocyte leakage at post-capillary venules ${ }^{[138]}$. Among six subfamilies, gelatinases (MMP-2 and MMP-9) are constitutively expressed in brain and best explored in MS pathogenesis ${ }^{[133]}$. Particularly, there is slightly more evidence about MMP-9 as a disease activity biomarker in MS, while results on MMP-2 are more controversial ${ }^{[141,142]}$.

Elevated levels of MMP-9 have been detected in serum and CSF of patients affected by MS and other neurological diseases compared with controls, showing an association with disease activity ${ }^{[143-149]}$. In a study by Lee and coworkers, higher values of MMP-9 were found during clinical relapses, also related to a greater number of MRI gadolinium-enhancing $(\mathrm{Gd}+)$ lesions ${ }^{[144]}$. Similarly, another study confirmed higher concentrations of CSF MMP-9 in MS patients compared with controls, more in RRMS compared with PPMS ones, but there was no unequivocal association with clinical disease activity ${ }^{[148]}$.

Considering the role in MMP inhibition played by tissue inhibitors of MMPs (TIMPs), the ratio MMP-9/ TIMPs has also been considered as an equally valid biomarker and has been found to be increased in the serum of MS patients compared with controls, accordingly to elevated MMP-9 levels ${ }^{[149]}$. 
An increased expression of MMP-9 in active MS lesions and in active borders of chronic lesions has been found in some studies employing brain tissue from MS patients ${ }^{[150,151]}$, confirming previous results and corroborating MMP-9 as a potentially valid disease activity biomarker.

Some studies have explored the variations of MMPs levels in patients under DMDs. A significant decrease in serum MMP-9 mRNA in RRMS patients under IFN- $\beta$ has been noted after a 12-month follow-up by Galboiz and coworkers ${ }^{[152]}$ and confirmed by other studies ${ }^{[153]}$. Among these, changes in MMP-9 levels occurred under IFN- $\beta$-treatment in a study by Comabella and coworkers, with a trend of reduction during the first 3 months and then an increase until reaching baseline values. Worthy of note, a significant increase in TIMP-1 concentrations occurred in the responder group compared with non-responders ${ }^{[154]}$. A possible response to NTZ treatment has also been explored. Balasa and coworkers reported a significant decrease in serum MMP-9 after 8 months of treatment and a good correlation between the biomarker and disease activity ${ }^{[155]}$, but this finding was not confirmed by other studies ${ }^{[156]}$. In NTZ-treated patients, decreased baseline levels of MMP-9 were found in patients who developed progressive multifocal leukoencephalopathy compared with those who did not ${ }^{[157]}$.

However, additional studies are needed for its validation, providing evidence of its role as a potential disease activity biomarker for MS.

\section{Myelin basic protein}

It has long been known that MBP is a potential disease activity biomarker for $\mathrm{MS}^{[158]}$, since it displays an acute damage to CNS myelin, despite not being specific for the disease ${ }^{[159]}$. MBP is a polypeptide that assures the preservation of myelin structure and membrane compaction ${ }^{[160]}$. Four human isoforms are known, one of them prevailing in adult CNS myelin as a polypeptide containing 170 amino acid residues $^{[161]}$. MBP contains multiple epitopes, with the ones recognized by monoclonal and polyclonal antibodies mainly allocated in 80-100 residues ${ }^{[161,162]}$. MBP-specific effector T lymphocytes have proved to play an essential role in the pathogenesis of experimental EAE models ${ }^{[163]}$, which is rather suppressed when $\mathrm{T}$ cells are inhibited by MBP-specific Tregs ${ }^{[164]}$.

Several studies have found increased CSF levels of MBP in patients with MS, temporally related to relapses $^{[158,159,165-167]}$ and detectable up to 5-6 weeks later ${ }^{[168]}$. Accordingly, RRMS patients with disease activity show higher values than progressive MS and stable patients ${ }^{[165]}$. CSF MBP concentrations are also greater when polysymptomatic and severe relapses occur, correlating with EDSS score and MRI activity and decreasing after corticosteroid treatment ${ }^{[168,169]}$. Zhou et al ${ }^{[170]}$ explored the association between MBP gene variations and MS course in a 5-year prospective study involving 127 patients with CIS, identifying a risk genotype (CT+TT of rs12959006) for the risk of conversion to MS, disability progression and relapses. MBP-like material has been found in the urine of MS patients as well, although its concentration fluctuates and does not seem to be temporally related to acute myelin damage. Conversely, higher values have been found in SPMS patients and are supposed to be related to disease progression ${ }^{[161]}$. Considering the role of MBP in the pathogenesis of MS and its potential role as a therapeutic target, several clinical trials have been carried out or are currently ongoing to evaluate possible new drugs ${ }^{[171-174]}$. However, this biomarker has not been validated and the preliminary results need to be replicated in additional cohorts.

\section{Neuronal cell adhesion molecule}

Neuronal cell adhesion molecule (N-CAM) is considered a marker of repair and remyelination ${ }^{[175]}$ and it is mainly expressed in the CNS, but its involvement in neoplastic diseases has also been documented ${ }^{[176]}$. During the development of the CNS, the polysialylated form of N-CAM is actively involved in myelination, axonal growth and neural cell migration ${ }^{[177]}$. It has been found to be expressed by neural precursors of oligodendrocytes, astrocytes and neurons, supporting the process of myelination in the olfactory bulb in mouse brain ${ }^{[177]}$. 
In animal models, increased N-CAM expression has been identified in astrocytes in acutely demyelinated $\operatorname{areas}^{[178]}$ and, similarly, in areas damaged by kainic acid ${ }^{[179]}$. Soluble forms of N-CAM have also been found to be involved in peripheral nerve myelination and repair, with Schwann cells expressing specific receptors for the molecule ${ }^{[177]}$. Both soluble and membrane-bound forms of this molecule exist, with different and little known expression and specific functions, and N-CAM belongs to the immunoglobulin superfamily ${ }^{[180]}$. Normal CSF values of soluble N-CAM range between 460 and 1,060 ng/mL ${ }^{[177]}$. Among several neurological diseases, CSF levels were found to be reduced in MS patients, who showed a mean value of $250 \pm 107 \mathrm{ng} / \mathrm{mL}$, compared with healthy controls (mean value of $412 \pm 109$ ), with similar findings when comparing patients affected by Alzheimer's disease and meningitis with controls, regardless of age and gender ${ }^{[180]}$. Moreover, PPMS patients exhibited lower levels compared with RRMS ones ${ }^{[181]}$. These data confirmed the results of a previous study showing lower soluble N-CAM concentrations in non-acute phase MS patients compared with controls and acute-phase MS patient ${ }^{[182]}$. In the last group, indeed, increased CSF N-CAM levels were noted, gradually increasing in the first week after relapse and correlating well with the remission of symptoms ${ }^{[183]}$. Moreover, comparing acute-phase patients who underwent steroid treatment with those who did not, significantly greater values were recorded in the first group ${ }^{[183]}$. However, steroid treatment does not determine an increase in N-CAM levels in itself, and this finding was not reported in non-acute phase MS patients who were treated ${ }^{[183]}$.

Among DMDs, NTZ and mitoxantrone proved to significantly increase N-CAM levels in MS patients, while fingolimod did not ${ }^{[181]}$.

Considering the evidence of lower N-CAM levels in PPMS compared to RRMS ${ }^{[181]}$, in RRMS compared to CIS, and in polyneuropathy compared to Guillain-Barré syndrome ${ }^{[180]}$, this molecule is actually considered mainly as an indicator of scarce repair capability more than a marker of severe neuronal damage ${ }^{[180]}$. However, it is not currently used in clinical practice and needs further validation ${ }^{[1,184]}$.

\section{Chitinase-3-like-1}

Chitinase-3-like-1 (CHI3L1) (or YKL-40) belongs to the family of chitinases, enzymes that catalyze the cleavage of chitin by hydrolysis. Its biological role in humans has not been definitely clarified, despite many proofs of its involvement in several processes exist, such as tissue remodeling, angiogenesis, tumorigenesis and inflammation ${ }^{[185]}$. Belonging to the same family, chitotriosidase is known to be associated with several diseases, including infectious and inflammatory ones ${ }^{[186]}$.

Though it is not a specific marker for MS, CSF CHI3L1 levels have been found to be increased in RRMS and NMO patients compared with controls, including healthy people, patients suffering from other inflammatory diseases and SPMS patients ${ }^{[185,187,188]}$. Conversely, serum CHI3L1 levels were not significantly different between groups in the aforementioned studies ${ }^{[185,187]}$. Elevated levels of CHI3L1 were also detected in both PPMS and SPMS compared with healthy controls ${ }^{[189]}$. Patients who fulfilled diagnostic criteria for active progressive MS or showed elevated levels of MMP-9 and CXCL13 also had higher concentrations of $\mathrm{CHI} 3 \mathrm{~L}_{1}{ }^{[189]}$. However, as a diagnostic biomarker, $\mathrm{CHI} 3 \mathrm{~L} 1$ needs further replication in additional cohorts ${ }^{[3]}$.

Particular attention has been given to the prognostic role of this molecule, whose CSF concentration has proved to be an independent predictor for the risk of conversion to clinically definite MS in CIS ${ }^{[187,190-192]}$, but not in $\mathrm{RIS}^{[32]}$. In a study by Comabella and coworkers, CSF CHI3L1 levels additionally correlated with shorter latency time of conversion and with disability progression during follow-up and radiological disease activity ${ }^{[190]}$.

In a large multicenter study involving 813 patients with CIS, the aforementioned results were confirmed. Not only CSF CHI3L1 concentration was associated with the risk of conversion to clinically definite MS, 
but it also was correlated with shorter time to conversion and to disability worsening, for which it was an independent risk factor ${ }^{[192]}$. As a consequence, there is strong evidence of its role as a biomarker able to predict CIS conversion, and it should be assessed for clinical implementation ${ }^{[3]}$.

As a treatment response biomarker, serum CHI3L1 levels were measured in 76 RRMS patients under IFN- $\beta$ treatment and were found to be increased in the non-responder group compared with the responder one. As there was such a difference since baseline, it was suggested that non-responders had higher disease activity and accordingly greater CSF CHI3L1 levels ${ }^{[193]}$.

\section{Other biomarkers requiring further validation}

Several T-cell cytokines have been explored as potential biomarkers for MS, but which are crucial in MS pathogenesis has not been entirely elucidated yet ${ }^{[194]}$.

IL-12 and IL-23 respectively induce the differentiation of naive T cells in IFN $\gamma$-producing Th1 cells and IL-17-producing Th17 cells ${ }^{[195]}$. Both interleukins increase the encephalitogenic potential of T lymphocytes, but only IL-23 has been found to be a critical molecule in the development of $\mathrm{EAE}^{[196]}$. On the basis of results coming from EAE models, where animals improved after administration of neutralizing antibodies against the shared IL-12/IL-23 p40 subunit, a phase II double-blind placebo-controlled trial with the monoclonal antibody ustekinumab was conducted in 249 RRMS patients, although it did not show substantial efficacy ${ }^{[197]}$.

Differently, IL-17 does not seem to be crucial to EAE development, though increasing its severity and atypical presentation, maybe through the recruiting of neutrophils and the effect of $\mathrm{MMPs}^{[194]}$. Nevertheless, increased IL-17 mRNA expression in mononuclear cells was found in MS lesions and in CSF and blood of MS patients ${ }^{[198,199]}$, and Th17 cells were found to undergo a more marked increase in CSF during MS relapses than Th1 cells, which usually prevail in both blood and $\mathrm{CSF}^{[200]}$. A monoclonal antibody against IL-17A (secukinumab) has proved to reduce MRI activity in MS, but further studies are needed ${ }^{[201]}$.

Tumor necrosis factor alpha (TNF- $\alpha$ ) is a cytokine involved in the pathogenesis of several autoimmune diseases, including MS, wherein increased CSF and serum levels of this molecule have been detected ${ }^{[202-204]}$. Today, it is known that TNF- $\alpha$ may exert different biological effects, depending on the involved receptor, both stimulating inflammatory processes and apoptosis (via TNF receptor 1) or inducing a pro-survival pathway and reducing inflammation (via TNF receptor 2). This might explain the failure and the unexpected results of treatment approaches with unselective anti-TNF- $\alpha$ drugs in MS patients, which lead to an increase in disease activity in $\mathrm{MS}^{[205,206]}$. The modulation of TNF- $\alpha$ signaling has provided promising results in EAE, whose remission has been induced by selective inhibition of the soluble form of TNF- $\alpha$, which mainly acts via TNF receptor $1^{[207]}$.

B cell-activating factor (BAFF), belonging to the TNF family, is a maturation and survival factor for B lymphocytes, whose serum levels have been found to be increased in several autoimmune diseases ${ }^{[208]}$. In MS, increased BAFF concentrations in CSF and in demyelinating lesions have been detected ${ }^{[209]}$. The association with disease activity has not been elucidated, since some controversial results have been reported ${ }^{[1,209]}$. Moreover, the clinical significance of increased BAFF levels under treatment with some DMDs is not clear ${ }^{[209]}$.

\section{PROGNOSTIC BIOMARKERS}

\section{Neurofilaments}

Neurofilaments (NFs) are components of the neuronal cytoskeleton, responsible for the increase in nerve conduction velocity in myelinated fibers and for their structural support ${ }^{[210]}$. Consisting of heavy (NF-H), 
medium (NF-M) and light (NF-L) chains ${ }^{[211]}$, their detection in CSF and blood samples has been the subject of interest for years. Several studies investigated the increase in NFs in several neurological diseases ${ }^{[212]}$, such as amyotrophic lateral sclerosis ${ }^{[213]}$, Alzheimer's disease ${ }^{[214]}$, frontotemporal dementia ${ }^{[215]}$, stroke ${ }^{[216]}$, $\mathrm{MS}^{[211]}$, Huntington disease ${ }^{[217]}$, atypical parkinsonian syndromes and neurocognitive impairment in HIVpositive individuals ${ }^{[218]}$.

In most cases, NFs have been investigated as a potential prognostic and disease activity marker related to axonal damage, speculating a relation between the quantitative amount of CSF and serum NFs and the rate of neurodegeneration ${ }^{[218]}$.

In MS, NFs have also been extensively examined as a diagnostic, disease activity and drug response biomarker. Moreover, serum NF-L levels, detected through a single molecule array (Simoa), appear strictly related to CSF levels ${ }^{[219-222]}$, despite being approximately 42 -fold lower ${ }^{[223]}$. Cut-off values have not been unequivocally established as for CSF ones. However, serum NF-L values between 16-20 pg/mL have been identified as a normal range among a heterogeneous group of healthy controls enrolled in various studies $^{[211]}$, without gender difference and with a trend to increase along with age-related physiological axonal damage ${ }^{[223]}$.

Particularly, while the detection of higher CSF NF-H levels in SPMS patients suggests a major correlation with chronic axonal damage and is accordingly age-related ${ }^{[24,225]}$, CSF NF-L seem to be better related to acute axonal damage due to inflammation. Indeed, increased levels of NF-L were found in CSF of MS patients compared with controls, with greater concentrations during exacerbations. Moreover, such high concentrations were associated with progression in both clinically stable patients and relapsing ones ${ }^{[226,227}$. A recent meta-analysis confirmed these results, finding higher CSF NF-L levels in RRMS patients compared with PMS and double concentrations in relapsing patients compared with remitting ones ${ }^{[228]}$.

In a longitudinal study involving 22 IFN $\beta$-1a- and riluzole-treated patients and 20 IFN $\beta$ - $1 \mathrm{a}$ - and placebotreated ones with early MS, serum NF-L concentrations were assessed over a 24-month period, correlating well with EDSS changes, Gd+ lesions and the development of brain atrophy. Moreover, increased serum NF-L levels were associated with worse results in neuropsychological tests assessing visuospatial functioning, recall and both verbal and non-verbal episodic learning ${ }^{[229]}$.

Similar results concerning the association between serum NF-L levels and cognitive impairment in early stages of $\mathrm{MS}^{[230]}$ and between serum NF-L concentrations and EDSS changes ${ }^{[231]}$ were confirmed by other studies, though not all agreed ${ }^{[232]}$. Despite correlating with EDSS in PMS patients, serum NF-L levels failed to correlate with EDSS progression in the previous year and during a median follow-up of 27 months. Particularly, serum NF-L increased in all PMS patients, including those who did not exhibit changes in EDSS or an increase in disability ${ }^{[232]}$.

In patients with RIS, increased CSF NF-L levels were found to be an independent risk factor for the conversion to CIS and MS. Matute-Blanch and coworkers considered a cut-off value equal to $619 \mathrm{ng} / \mathrm{L}$, since greater values were related to shorter times of conversion ${ }^{[32]}$. CSF NF-L concentrations have been found to be increased in patients with CIS as well ${ }^{[233]}$, with greater ones in those who converted to clinically definite $\mathrm{MS}^{[224,234]}$. Despite these promising results, their role as prognostic biomarker for CIS conversion is still weak, and replication in larger cohorts is needed to confirm it ${ }^{[3]}$.

In 86 CIS patients with optic neuritis as the first clinical event, CSF NF-L levels also predicted long-term cognitive and physical disability over a follow-up period ranging between 9 and 19 years ${ }^{[235]}$. 
As a disease activity and prognostic biomarker, the amount of CSF NF-L levels showed a significant association with NEDA-3 status, MRI activity and brain atrophy and significantly correlated with serum NF-L ones ${ }^{[11]}$. In several studies, serum NF-L also correlated with MRI activity, predicted the development of brain volume loss in a period of 2 years and decreased under DMDs ${ }^{[236,237]}$. A recent study obtained similar results, with serum NF-L detected in early phases contributing to the prediction of lesion load and brain volume loss over a period of 10 years ${ }^{[238]}$.

CSF NF-L concentrations proved to decrease after 12-24 months of immunosuppressive therapy in active progressive MS patients ${ }^{[239]}$ and after switching from first-line therapies to fingolimod in RRMS ones ${ }^{[240]}$. Moreover, compared with NF-H, CSF NF-L has been found to be superior as a therapeutic biomarker after 12 months of NTZ-treatment in RRMS patients ${ }^{[241,242]}$. Nevertheless, the potential role of CSF NF-L as a treatment response biomarker is severely limited by the invasiveness of performing serial lumbar punctures. Conversely, serial serum NF-L assessments would represent a more easily detectable marker and a reliable indicator of CSF NF-L levels ${ }^{[219,221]}$. Results from a recent study conducted on 15 MS patients treated with alemtuzumab and monitored with serial serum NF-L measurements were significant ${ }^{[243]}$. Indeed, serum NF-L levels correlated well with clinical and radiological activity at baseline and during follow-up, decreasing within 6 months from drug administration until reaching stable values under $8 \mathrm{pg} / \mathrm{ml}$ in those patients who achieved NEDA-3. Moreover, patients who showed clinical and radiological disease activity during follow-up also exhibited increased levels of serum NF-L up to 5 months before relapses.

So far, several studies have confirmed the reliability of NF-L as a disease activity and treatment response biomarker for MS, even though it does not represent a MS-specific biomarker. However, a precise cut-off is still missing, precluding the chance to stratify the risk of clinical and radiological disease activity according to NF-L levels. The opportunity to consider only intra-individual values is still debated, without focusing on their deviation from values reported in healthy people ${ }^{[237]}$.

Further replication in larger, multicenter cohorts is needed. A randomized controlled trial, prospectively recruiting 900 patients from 45 sites in the USA, will provide further information about the potential role of serum NF-L as a prognostic and treatment response biomarker for $\mathrm{MS}^{[244]}$.

\section{IgM oligoclonal bands}

Unlike small and monomeric IgG, IgM are large molecules consisting of pentameter units and ten antigen-binding sites and are strong activators of complement ${ }^{[245]}$. In a similar way to CSF IgG OCB, their identification is considered a sign of intrathecal synthesis, suggesting an inflammatory disease of the $\mathrm{CNS}^{[246]}$. However, CSF IgM oligoclonal bands (IgM OCB) are mainly considered a prognostic and disease activity biomarker than a diagnostic one, though not routinely used in clinical practice ${ }^{[1]}$.

In a study involving $29 \mathrm{MS}$ patients who were followed-up for 5 to 16 years, the presence of CSF IgM OCB was strongly associated with conversion to SPMS and the achievement of greater EDSS scores ${ }^{[24]}$. In a similar way, IgM OCB-positivity strongly predicted a severe disease course influencing the probability of developing greater disability in a cohort of $64 \mathrm{MS}$ patients ${ }^{[248]}$.

In patients with CIS, the identification of CSF lipid-specific IgM OCB was associated with greater MRI lesion load and brain atrophy at the first clinical event ${ }^{[249]}$ and with an aggressive disease course $\mathrm{e}^{[250]}$. Periventricular lesion load during the first years of disease proved to be related as well to the entity of IgM intrathecal synthesis in CIS patients, so that an active role of IgM in the development of demyelinating lesions has been supposed ${ }^{[251]}$.

Moreover, both the risk of a second clinical event and its earliness were strongly increased when both CSF lipid-specific IgM OCB and IgG OCB were detected, as in $22 \%$ of 192 patients with $\mathrm{CIS}^{[252]}$. In another 
study by Ferraro and coworkers, the identification of CSF IgM OCB in CIS patients was predictive of the occurrence of another relapse within a year ${ }^{[253]}$. Results from a blinded multicenter study involving 52 neurological patients and 13 centers confirmed the reproducibility of the test ${ }^{[254]}$. However, further confirmatory studies in additional cohorts are needed, and IgM OCB detection currently has an intermediate level of evidence as a predictive biomarker for CIS conversion ${ }^{[3]}$.

The presence of CSF IgM OCB has been also associated with a severe disease course in RRMS patients, while it seems to be less frequent among PPMS compared with RRMS ones ${ }^{[25]}$. Strong evidence of its value as a prognostic biomarker for RRMS exists ${ }^{[3,249]}$, so its potential clinical implementation has to be evaluated.

Finally, there is little evidence for the possible interactions between DMDs and CSF IgM OCB. The response to IFN- $\beta$ treatment in RRMS seems to be reduced in patients exhibiting CSF lipid-specific IgM $\mathrm{OCB}$, who showed a minor reduction in relapse rate and a higher probability of achieving greater EDSS values ${ }^{[256]}$.

NTZ has proved to reduce serum IgM and IgG levels after 2 years of treatment in a time-dependent manner ${ }^{[257]}$. In a study by Villar and coworkers, NTZ determined a decrease in CSF IgM OCB in patients with no active disease, with complete disappearance in $70 \%$ of them, while no effects were reported in those with active disease ${ }^{[258]}$.

\section{Glial fibrillary acidic protein}

Glial fibrillary acidic protein (GFAP) is highly expressed in the cytoskeleton of astrocytes, and it belongs to the family of intermediate filaments, which are highly cell type specific ${ }^{[259]}$. Since GFAP is upregulated in astroglial cell activation (astrogliosis), occurring in many inflammatory and non-inflammatory diseases $^{[167,259-261]}$, it has been explored as a biomarker for MS. Particularly, reactive astrocytes proved to be actively involved in neurodegenerative diseases, probably losing their protective role and developing neurotoxic functions ${ }^{[262-264]}$. The glial scar itself, which physically protects a damaged area, may also physically obstruct remyelination ${ }^{[264]}$. Finally, A1 astrocytes were found in MS lesions, as in EAE models where they were associated with neuronal and oligodendrocytic death ${ }^{[262]}$. On the basis of these remarks, an association between GFAP and disability in MS has been investigated. Elevated CSF GFAP levels were found in MS patients compared with controls ${ }^{[265-267]}$, showing higher concentrations in patients with EDSS greater than 6.5 compared with those with minor disability ${ }^{[266]}$. In a study by Högel and coworkers, serum levels of GFAP proved to be associated with a greater EDSS score as well, but also with longer disease duration and progressive course ${ }^{[268]}$. On this issue, positive correlations have been found between CSF GFAP and disease duration, likewise between serum GFAP and disease severity, in a cohort of 93 PPMS patients ${ }^{[264]}$. In a study by Axelsson and coworkers, the increased levels of GFAP in MS patients were predictive for disability resulting 8-10 years later, confirming the association of this molecule with disability and progression in MS patients ${ }^{[267]}$. A similar result was obtained in a more recent longitudinal study involving 301 patients with CIS/MS with a mean follow-up time of 11 years, showing a correlation between GFAP levels and an early progression in the EDSS score ${ }^{[234]}$. However, further studies are needed to confirm its role as a prognostic biomarker for MS.

Evidence of an association between GFAP and high disease activity also exists, showing correlation with MRI parameters such as infratentorial chronic lesion load and the intensity of Gd+ in both CIS and RRMS patients ${ }^{[269]}$. Effectively, there is evidence that GFAP may increase in CSF and serum soon after (4-24 h) traumatic brain injuries, as a marker of acute lesion ${ }^{[261]}$. Due to its high cell type specificity and good correlation with neuronal degeneration, GFAP is currently considered a potential prognostic biomarker for progression $^{[4]}$. 


\section{CONCLUSION}

Research on biological markers is very active and current. At present, there are few molecules available, considering the hundreds under investigation. But they are continuously increasing due to a greater knowledge of MS and its underlying physiopathology. For instance, there are no clinically useful disease activity biomarkers, despite the large number of exploratory molecules described for this functional group.

As for the group of diagnostic biomarkers, previously dominated by IgG OCB analysis, the possibility to rely on quantitative, less expensive and less time-consuming assessments as a first-line screening, is moving forward.

Though it is true that CSF is the most suitable means for getting information about CNS physiopathology ${ }^{[15]}$, it is equally true that much of interest is moving towards serum biomarkers. For quite some time, their clinical use has been limited by both a greater variability and very low concentrations, a problem overcome by the introduction of increasingly sophisticated tools (e.g., the detection of serum NF-L levels through Simoa $)^{[222]}$. Furthermore, treatment response biomarkers, such as anti-IFN- $\beta$ and anti-NTZ antibodies, are mainly determined in serum and have not been included in this review, which is focused on CSF biomarkers. Despite requiring a more invasive approach, CSF still represents a unique source of data about the CNS, enough to have been defined as a "liquid biopsy" of $\mathrm{CNS}^{[4]}$. This is even more true since the histological analysis of brain tissue cannot be routinely performed and almost any study on new potential biomarkers has to start from CSF analysis. There is no doubt that we are now able to diagnose and treat patients in early phases and even wondering about treating asymptomatic patients with only radiological signs suggestive of the disease. Thinking of how MS diagnosis has been revolutionized by MRI in the last 20 years, it would not be impressive if new and promising biomarkers might lead to a new revolution in MS in the coming years.

\section{HIGHLIGHTS}

1. CSF is a unique source of potential biomarkers for MS, despite requiring a certain invasiveness for its collection.

2. Only CSF diagnostic biomarkers are currently used in clinical practice, though hundreds of molecules have been validated as disease activity and prognostic biomarkers.

3. IgG OCB maintain a prominent role as a validated diagnostic biomarker and are considered an alternative tool to MRI which can substitute for dissemination in time according to the 2017 revision of McDonald criteria. They also retain a prognostic role for conversion to MS when detected in patients with CIS.

4. NF-L has proved to be a useful biomarker as indicator of disease activity in MS. The possibility of measuring NF-L at different time points through serum detection makes it also suitable for the monitoring of treatment response.

5. KFLC index has proved to be a more sensitive but less specific diagnostic biomarker compared with IgG $\mathrm{OCB}$, representing a potential first-line assessment in patients with suspected MS and reducing the request for IgG OCB analysis. It has a role as a prognostic for CIS conversion biomarker as well, but the lack of a universal cut-off value still represents a limit.

6. IgM OCB show good potential as a prognostic biomarker, since they are associated with an aggressive disease course, a higher risk of conversion to MS in CIS patients, disability progression and conversion to SPMS.

7. Several disease activity biomarkers seem promising, though requiring further validation. Increased levels of NO metabolites, OPN, MBP, MMP-9, N-CAM, CXCL13 and CHI3L1 have been detected in a close temporal correlation with relapses. 


\section{DECLARATIONS}

\section{Authors' contributions}

The conception and design of the study, conducted the literature review, drafted the manuscript: Toscano S The conception and design of the study, and provided critical revision and final approval of the article: Patti F

\section{Availability of data and materials}

Not applicable.

\section{Financial support and sponsorship}

None.

\section{Conflicts of interest}

Both authors declared that there are no conflicts of interest.

\section{Ethical approval and consent to participate}

Not applicable.

\section{Consent for publication}

Not applicable.

\section{Copyright}

(C) The Author(s) 2021.

\section{REFERENCES}

1. Comabella M, Montalban X. Body fluid biomarkers in multiple sclerosis. Lancet Neurol 2014;13:113-26.

2. Frisoni GB, Boccardi M, Barkhof F, Blennow K, Cappa S, et al. Strategic roadmap for an early diagnosis of Alzheimer's disease based on biomarkers. Lancet Neurol 2017;16:661-76.

3. Teunissen CE, Malekzadeh A, Leurs C, Bridel C, Killestein J. Body fluid biomarkers for multiple sclerosis--the long road to clinical application. Nat Rev Neurol 2015;11:585-96.

4. Giovannoni G. Multiple sclerosis cerebrospinal fluid biomarkers. Dis Markers 2006;22:187-96.

5. Ziemssen T, Akgün K, Brück W. Molecular biomarkers in multiple sclerosis. J Neuroinflammation 2019;16:272.

6. Trapp BD, Peterson J, Ransohoff RM, Rudick R, Mörk S, et al. Axonal transection in the lesions of multiple sclerosis. N Engl J Med 1998;338:278-85.

7. FDA News Release. FDA approves new oral drug to treat multiple sclerosis. Available from: http://www.fda.gov/news-events/pressannouncements/fda-approves-new-oral-drug-treat-multiple-sclerosis. [Last accessed on 2 Jul 2020]

8. FDA News Release. FDA approves new drug to treat multiple sclerosis. Available from: http://www.fda.gov/news-events/pressannouncements/fda-approves-new-drug-treat-multiple-sclerosis. [Last accessed on 2 Jul 2020]

9. Comi G. Induction vs. escalating therapy in multiple sclerosis: practical implications. Neurol Sci 2008;29 Suppl 2:S253-5.

10. Giovannoni G, Tomic D, Bright JR, Havrdová E. "No evident disease activity": The use of combined assessments in the management of patients with multiple sclerosis. Mult Scler 2017;23:1179-87.

11. Håkansson I, Tisell A, Cassel P, Blennow K, Zetterberg H, et al. Neurofilament levels, disease activity and brain volume during follow-up in multiple sclerosis. J Neuroinflammation 2018;15:209.

12. Pandit L. No evidence of disease activity (NEDA) in multiple sclerosis - shifting the goal posts. Ann Indian Acad Neurol 2019;22:261-3.

13. FDA-NIH Biomarker Working Group. BEST (Biomarkers, EndpointS, and other Tools) Resource [Internet]. Available from: https://www. ncbi.nlm.nih.gov/books/NBK338448/. [Last accessed on 2 Jul 2020]

14. Rush CA, MacLean HJ, Freedman MS. Aggressive multiple sclerosis: proposed definition and treatment algorithm. Nat Rev Neurol 2015;11:379-89.

15. Johanson CE, Duncan JA 3rd, Klinge PM, Brinker T, Stopa EG, et al. Multiplicity of cerebrospinal fluid functions: new challenges in health and disease. Cerebrospinal Fluid Res 2008;5:10.

16. Dobson R, Ramagopalan S, Davis A, Giovannoni G. Cerebrospinal fluid oligoclonal bands in multiple sclerosis and clinically isolated syndromes: a meta-analysis of prevalence, prognosis and effect of latitude. J Neurol Neurosurg Psychiatry 2013;84:909-14.

17. Imrell K, Landtblom AM, Hillert J, Masterman T. Multiple sclerosis with and without CSF bands: clinically indistinguishable but immunogenetically distinct. Neurology 2006;67:1062-4. 
18. Andersson M, Alvarez-Cermeño J, Bernardi G, Cogato I, Fredman P, et al. Cerebrospinal fluid in the diagnosis of multiple sclerosis: a consensus report. J Neurol Neurosurg Psychiatry 1994;57:897-902.

19. Freedman MS, Thompson EJ, Deisenhammer F, Giovannoni G, Grimsley G, et al. Recommended standard of cerebrospinal fluid analysis in the diagnosis of multiple sclerosis: a consensus statement. Arch Neurol 2005;62:865-70.

20. Thompson AJ, Banwell BL, Barkhof F, Carroll WM, Coetzee T, et al. Diagnosis of multiple sclerosis: 2017 revisions of the McDonald criteria. Lancet Neurol 2018;17:162-73.

21. Schwenkenbecher P, Wurster U, Konen FF, Gingele S, Sühs KW, et al. Impact of the McDonald criteria 2017 on early diagnosis of relapsing-remitting multiple sclerosis. Front Neurol 2019;10:188.

22. Poser CM, Paty DW, Scheinberg L, McDonald WI, Davis FA, et al. New diagnostic criteria for multiple sclerosis: guidelines for research protocols. Ann Neurol 1983;13:227-31.

23. McDonald WI, Compston A, Edan G, Goodkin D, Hartung P, et al. Recommended diagnostic criteria for multiple sclerosis: guidelines from the International Panel on the diagnosis of multiple sclerosis. Ann Neurol 2001;50:121-7.

24. Polman CH, Reingold SC, Edan G, Filippi M, Hartung HP, et al. Diagnostic criteria for multiple sclerosis: 2005 revisions to the "McDonald Criteria." Ann Neurol 2005;58:840-6.

25. Polman CH, Reingold SC, Banwell B, Clanet M, Cohen JA, et al. Diagnostic criteria for multiple sclerosis: 2010 revisions to the McDonald criteria. Ann Neurol 2011;69:292-302.

26. Sandberg-Wollheim M, Olsson T. Cerebrospinal fluid oligoclonal bands are important in the diagnosis of multiple sclerosis, unreasonably downplayed by the McDonald criteria 2010: Yes. Mult Scler 2013;19:714-6.

27. Arrambide G, Tintore M, Espejo C, Auger C, Castillo M, et al. The value of oligoclonal bands in the multiple sclerosis diagnostic criteria. Brain 2018;141:1075-84.

28. Tintoré M, Rovira A, Brieva L, Grivé E, Jardí R, et al. Isolated demyelinating syndromes: comparison of CSF oligoclonal bands and different MR imaging criteria to predict conversion to CDMS. Mult Scler 2001;7:359-63.

29. Tintoré M, Rovira A, Río J, Tur C, Pelayo R, et al. Do oligoclonal bands add information to MRI in first attacks of multiple sclerosis? Neurology 2008;70:1079-83.

30. Boyko A. Radiologically isolated syndrome with oligoclonal bands in CSF (RIS + OCB) can be classified as high MS risk group. Mult Scler 2020;26:869-70.

31. Makhani N, Lebrun C, Siva A, Narula S, Wassmer E, et al; Observatoire Francophone de la Sclérose en Plaques (OFSEP), Société Francophone de la Sclérose en Plaques (SFSEP), the Radiologically Isolated Syndrome Consortium (RISC) and the Pediatric Radiologically Isolated Syndrome Consortium (PARIS). Oligoclonal bands increase the specificity of MRI criteria to predict multiple sclerosis in children with radiologically isolated syndrome. Mult Scler J Exp Transl Clin 2019;5:2055217319836664.

32. Matute-Blanch C, Villar LM, Álvarez-Cermeño JC, Rejdak K, Evdoshenko E, et al. Neurofilament light chain and oligoclonal bands are prognostic biomarkers in radiologically isolated syndrome. Brain 2018;141:1085-93.

33. Pryce G, Baker D. Oligoclonal bands in multiple sclerosis; Functional significance and therapeutic implications. Does the specificity matter? Mult Scler Relat Disord 2018;25:131-7.

34. Rejdak K, Stelmasiak Z, Grieb P. Cladribine induces long lasting oligoclonal bands disappearance in relapsing multiple sclerosis patients: 10-year observational study. Mult Scler Relat Disord 2019;27:117-20.

35. Mancuso R, Franciotta D, Rovaris M, Caputo D, Sala A, et al. Effects of natalizumab on oligoclonal bands in the cerebrospinal fluid of multiple sclerosis patients: a longitudinal study. Mult Scler 2014;20:1900-3.

36. von Glehn F, Farias AS, de Oliveira AC, Damasceno A, Longhini AL, et al. Disappearance of cerebrospinal fluid oligoclonal bands after natalizumab treatment of multiple sclerosis patients. Mult Scler 2012;18:1038-41.

37. Harrer A, Tumani H, Niendorf S, Lauda F, Geis C, et al. Cerebrospinal fluid parameters of B cell-related activity in patients with active disease during natalizumab therapy. Mult Scler 2013;19:1209-12.

38. Koch M, Heersema D, Mostert J, Teelken A, De Keyser J. Cerebrospinal fluid oligoclonal bands and progression of disability in multiple sclerosis. Eur J Neurol 2007;14:797-800.

39. Link H, Tibbling G. Principles of albumin and IgG analyses in neurological disorders. III. Evaluation of IgG synthesis within the central nervous system in multiple sclerosis. Scand J Clin Lab Invest 1977;37:397-401.

40. Mayringer I, Timeltaler B, Deisenhammer F. Correlation between the IgG index, oligoclonal bands in CSF, and the diagnosis of demyelinating diseases. Eur J Neurol 2005;12:527-30.

41. Link H, Huang YM. Oligoclonal bands in multiple sclerosis cerebrospinal fluid: an update on methodology and clinical usefulness. J Neuroimmunol 2006;180:17-28.

42. Lefvert AK, Link H. IgG production within the central nervous system: a critical review of proposed formulae. Ann Neurol 1985;17:13-20.

43. Senel M, Tumani H, Lauda F, Presslauer S, Mojib-Yezdani R, et al. Cerebrospinal fluid immunoglobulin kappa light chain in clinically isolated syndrome and multiple sclerosis. PLoS One 2014;9:e88680.

44. Izquierdo G, Angulo S, Garcia-Moreno JM, Gamero MA, Navarro G, et al. Intrathecal IgG synthesis: marker of progression in multiple sclerosis patients. Acta Neurol Scand 2002;105:158-63.

45. Klein A, Selter RC, Hapfelmeier A, Berthele A, Müller-Myhsok B, et al. CSF parameters associated with early MRI activity in patients with MS. Neurol Neuroimmunol Neuroinflamm 2019;6:e573.

46. Gastaldi M, Zardini E, Franciotta D. An update on the use of cerebrospinal fluid analysis as a diagnostic tool in multiple sclerosis. Expert Rev Mol Diagn 2017;17:31-46.

47. Hegen H, Walde J, Milosavljevic D, Aboulenein-Djamshidian F, Senel M, et al. Free light chains in the cerebrospinal fluid. Comparison 
of different methods to determine intrathecal synthesis. Clin Chem Lab Med 2019;57:1574-86.

48. Kaplan B, Aizenbud BM, Golderman S, Yaskariev R, Sela BA. Free light chain monomers in the diagnosis of multiple sclerosis. J Neuroimmunol 2010;229:263-71.

49. Hassan-Smith G, Durant L, Tsentemeidou A, Assi LK, Faint JM, et al. High sensitivity and specificity of elevated cerebrospinal fluid kappa free light chains in suspected multiple sclerosis. J Neuroimmunol 2014;276:175-9.

50. Desplat-Jégo S, Feuillet L, Pelletier J, Bernard D, Chérif AA, et al. Quantification of immunoglobulin free light chains in cerebrospinal fluid by nephelometry. J Clin Immunol 2005;25:338-45.

51. Duranti F, Pieri M, Centonze D, Buttari F, Bernardini S, et al. Determination of $\kappa F L C$ and $\kappa$ Index in cerebrospinal fluid: a valid alternative to assess intrathecal immunoglobulin synthesis. J Neuroimmunol 2013;263:116-20.

52. Zeman D, Kušnierová $\mathrm{P}$, Bartoš V, Hradílek P, Kurková B, et al. Quantitation of free light chains in the cerebrospinal fluid reliably predicts their intrathecal synthesis. Ann Clin Biochem 2016;53:174-6.

53. Pieri M, Storto M, Pignalosa S, Zenobi R, Buttari F, et al. KFLC index utility in multiple sclerosis diagnosis: further confirmation. J Neuroimmunol 2017;309:31-3.

54. Crespi I, Vecchio D, Serino R, Saliva E, Virgilio E, et al. K index is a reliable marker of intrathecal synthesis, and an alternative to IgG index in multiple sclerosis diagnostic work-up. J Clin Med 2019;8:446.

55. Puthenparampil M, Altinier S, Stropparo E, Zywicki S, Poggiali D, et al. Intrathecal K free light chain synthesis in multiple sclerosis at clinical onset associates with local IgG production and improves the diagnostic value of cerebrospinal fluid examination. Mult Scler Relat Disord 2018;25:241-5.

56. Gaetani L, Di Carlo M, Brachelente G, Valletta F, Eusebi P, et al. Cerebrospinal fluid free light chains compared to oligoclonal bands as biomarkers in multiple sclerosis. J Neuroimmunol 2020;339:577108.

57. Gurtner KM, Shosha E, Bryant SC, Andreguetto BD, Murray DL, et al. CSF free light chain identification of demyelinating disease: comparison with oligoclonal banding and other CSF indexes. Clin Chem Lab Med 2018;56:1071-80.

58. Presslauer S, Milosavljevic D, Huebl W, Aboulenein-Djamshidian F, Krugluger W, et al. Validation of kappa free light chains as a diagnostic biomarker in multiple sclerosis and clinically isolated syndrome: a multicenter study. Mult Scler 2016;22:502-10.

59. Leurs CE, Twaalfhoven H, Lissenberg-Witte BI, van Pesch V,Dujmovic I, et al. Kappa free light chains is a valid tool in the diagnostics of MS: a large multicenter study. Mult Scler 2020;26:912-23.

60. Makshakov G, Nazarov V, Kochetova O, Surkova E, Lapin S, et al. Diagnostic and prognostic value of the cerebrospinal fluid concentration of immunoglobulin free light chains in clinically isolated syndrome with conversion to multiple sclerosis. PLoS One 2015;10:e143375.

61. Presslauer S, Milosavljevic D, Huebl W, Parigger S, Schneider-Koch G, et al. Kappa free light chains: diagnostic and prognostic relevance in MS and CIS. PLoS One 2014;9:e89945.

62. Presslauer S, Milosavljevic D, Brücke T, Bayer P, Hübl W. Elevated levels of kappa free light chains in CSF support the diagnosis of multiple sclerosis. J Neurol 2008;255:1508-14.

63. Ferraro D, Trovati A, Bedin R, Natali P, Franciotta D, et al. Cerebrospinal fluid kappa and lambda free light chains in oligoclonal bandnegative patients with suspected multiple sclerosis. Eur J Neurol 2020;27:461-7.

64. Vecchio D, Crespi I, Virgilio E, Naldi P, Campisi MP, et al. Kappa free light chains could predict early disease course in multiple sclerosis. Mult Scler Relat Disord 2019;30:81-4.

65. Rinker JR 2nd, Trinkaus K, Cross AH. Elevated CSF free kappa light chains correlate with disability prognosis in multiple sclerosis. Neurology 2006;67:1288-90.

66. Rudick RA, Medendorp SV, Namey M, Boyle S, Fischer J. Multiple sclerosis progression in a natural history study: predictive value of cerebrospinal fluid free kappa light chains. Mult Scler 1995;1:150-5.

67. Rathbone E, Durant L, Kinsella J, Parker AR, Hassan-Smith G, et al. Cerebrospinal fluid immunoglobulin light chain ratios predict disease progression in multiple sclerosis. J Neurol Neurosurg Psychiatry 2018;89:1044-9.

68. Felgenhauer K, Reiber H. The diagnostic significance of antibody specificity indices in multiple sclerosis and herpes virus induced diseases of the nervous system. Clin Investig 1992;70:28-37.

69. Tumani H, Tourtellotte WW, Peter JB, Felgenhauer K, The Optic Neuritis Study Group. Acute optic neuritis: combined immunological markers and magnetic resonance imaging predict subsequent development of multiple sclerosis. J Neurol Sci 1998;155:44-9.

70. Brettschneider J, Tumani H, Kiechle U, Muche R, Richards G, et al. IgG antibodies against measles, rubella, and varicella zoster virus predict conversion to multiple sclerosis in clinically isolated syndrome. PLoS One 2009;4:e7638.

71. Reiber H, Ungefehr S, Jacobi C. The intrathecal, polyspecific and oligoclonal immune response in multiple sclerosis. Mult Scler 1998;4:111-7.

72. Hottenrott T, Schorb E, Fritsch K, Dersch R, Berger B, et al. The MRZ reaction and a quantitative intrathecal IgG synthesis may be helpful to differentiate between primary central nervous system lymphoma and multiple sclerosis. J Neurol 2018;265:1106-14.

73. Jarius S, Eichhorn P, Franciotta D, Petereit HF, Akman-Demir G, et al. The MRZ reaction as a highly specific marker of multiple sclerosis: re-evaluation and structured review of the literature. J Neurol 2017;264:453-66.

74. Franciotta D, Salvetti M, Lolli F, Serafini B, Aloisi F. B cells and multiple sclerosis. Lancet Neurol 2008;7:852-8.

75. Godec MS, Asher DM, Murray RS, Shin ML, Greenham LW, et al. Absence of measles, mumps, and rubella viral genomic sequences from multiple sclerosis brain tissue by polymerase chain reaction. Ann Neurol 1992;32:401-4.

76. Ibitoye R, Kemp K, Rice C, Hares K, Scolding N, et al. Oxidative stress-related biomarkers in multiple sclerosis: a review. Biomark Med 2016;10:889-902. 
77. Smith KJ, Lassmann H. The role of nitric oxide in multiple sclerosis. Lancet Neurol 2002;1:232-41.

78. Yamashita T, Ando Y, Obayashi K, Uchino M, Ando M. Changes in nitrite and nitrate (NO2-/NO3-) levels in cerebrospinal fluid of patients with multiple sclerosis. J Neurol Sci 1997;153:32-4.

79. Miljkovic Dj, Drulovic J, Trajkovic V, Mesaros S, Dujmovic I, et al. Nitric oxide metabolites and interleukin-6 in cerebrospinal fluid from multiple sclerosis patients. Eur J Neurol 2002;9:413-8.

80. Yuceyar N, Taşkiran D, Sağduyu A. Serum and cerebrospinal fluid nitrite and nitrate levels in relapsing-remitting and secondary progressive multiple sclerosis patients. Clin Neurol Neurosurg 2001;103:206-11.

81. Giovannoni G, Heales S, Silver N, O'riordan J, Miller R, et al. Raised serum nitrate and nitrite levels in patients with multiple sclerosis. J Neurol Sci 1997;145:77-81.

82. Haghikia A, Kayacelebi AA, Beckmann B, Hanff E, Gold R, et al. Serum and cerebrospinal fluid concentrations of homoarginine, arginine, asymmetric and symmetric dimethylarginine, nitrite and nitrate in patients with multiple sclerosis and neuromyelitis optica. Amino Acids 2015;47:1837-45.

83. Giovannoni G, Silver NC, O’Riordan J, Miller RF, Heales SJ, et al. Increased urinary nitric oxide metabolites in patients with multiple sclerosis correlates with early and relapsing disease. Mult Scler 1999;5:335-41.

84. Calabrese V, Scapagnini G, Ravagna A, Bella R, Foresti R, et al. Nitric oxide synthase is present in the cerebrospinal fluid of patients with active multiple sclerosis and is associated with increases in cerebrospinal fluid protein nitrotyrosine and S-nitrosothiols and with changes in glutathione levels. J Neurosci Res 2002;70:580-7.

85. Hua LL, Liu JS, Brosnan CF, Lee SC. Selective inhibition of human glial inducible nitric oxide synthase by interferon-beta: implications for multiple sclerosis. Ann Neurol 1998;43:384-7.

86. Danilov AI, Andersson M, Bavand N, Wiklund N, Olsson T, et al. Nitric oxide metabolite determinations reveal continuous inflammation in multiple sclerosis. J Neuroimmunol 2003;136:112-8.

87. Giovannoni G, Miller DH, Losseff NA, Sailer M, Lewellyn-Smith N, et al. Serum inflammatory markers and clinical/MRI markers of disease progression in multiple sclerosis. J Neurol 2001;248:487-95.

88. Tavazzi B, Batocchi AP, Amorini AM, Nociti V, D’Urso S, et al. Serum metabolic profile in multiple sclerosis patients. Mult Scler Int 2011;2011:167156.

89. Svenningsson A, Petersson AS, Andersen O, Hansson GK. Nitric oxide metabolites in CSF of patients with MS are related to clinical disease course. Neurology 1999;53:1880-2.

90. Acar G, Idiman F, Idiman E, Kirkali G, Cakmakçi H, et al. Nitric oxide as an activity marker in multiple sclerosis. J Neurol 2003;250:588-92.

91. Sellebjerg F, Giovannoni G, Hand A, Madsen H, Jensen C, et al. Cerebrospinal fluid levels of nitric oxide metabolites predict response to methylprednisolone treatment in multiple sclerosis and optic neuritis. J Neuroimmunol 2002;125:198-203.

92. Rejdak K, Eikelenboom MJ, Petzold A, Thompson EJ, Stelmasiak Z, et al. CSF nitric oxide metabolites are associated with activity and progression of multiple sclerosis. Neurology 2004;63:1439-45.

93. Merry K, Dodds R, Littlewood A, Gowen M. Expression of osteopontin mRNA by osteoclasts and osteoblasts in modelling adult human bone. J Cell Sci 1993;104:1013-20.

94. Del Prete A, Scutera S, Sozzani S, Musso T. Role of osteopontin in dendritic cell shaping of immune responses. Cytokine Growth Factor Rev 2019;50:19-28.

95. Murugaiyan G, Mittal A, Weiner HL. Increased osteopontin expression in dendritic cells amplifies IL-17 production by CD4+ T cells in experimental autoimmune encephalomyelitis and in multiple sclerosis. J Immunol 2008;181:7480-8.

96. Braitch M, Constantinescu CS. The role of osteopontin in experimental autoimmune encephalomyelitis (EAE) and multiple sclerosis (MS). Inflamm Allergy Drug Targets 2010;9:249-56.

97. Sato W, Tomita A, Ichikawa D, Lin Y, Kishida H, et al. CCR2(+)CCR5(+) T cells produce matrix metalloproteinase-9 and osteopontin in the pathogenesis of multiple sclerosis. J Immunol 2012;189:5057-65.

98. Chabas D, Baranzini SE, Mitchell D, Bernard CC, Rittling SR, et al. The influence of the proinflammatory cytokine, osteopontin, on autoimmune demyelinating disease. Science 2001;294:1731-5.

99. Sinclair C, Mirakhur M, Kirk J, Farrell M, McQuaid S. Up-regulation of osteopontin and alphaBeta-crystallin in the normal-appearing white matter of multiple sclerosis: an immunohistochemical study utilizing tissue microarrays. Neuropathol Appl Neurobiol 2005;31:292303.

100. Vogt MH, Lopatinskaya L, Smits M, Polman CH, Nagelkerken L. Elevated osteopontin levels in active relapsing-remitting multiple sclerosis. Ann Neurol 2003;53:819-22.

101. Agah E, Zardoui A, Saghazadeh A, Ahmadi M, Tafakhori A, et al. Osteopontin (OPN) as a CSF and blood biomarker for multiple sclerosis: A systematic review and meta-analysis. PLoS One 2018;13:e0190252.

102. Shimizu Y, Ota K, Ikeguchi R, Kubo S, Kabasawa C, et al. Plasma osteopontin levels are associated with disease activity in the patients with multiple sclerosis and neuromyelitis optica. J Neuroimmunol 2013;263:148-51.

103. Chowdhury SA, Lin J, Sadiq SA. Specificity and correlation with disease activity of cerebrospinal fluid osteopontin levels in patients with multiple sclerosis. Arch Neurol 2008;65:232-5.

104. Comabella M, Pericot I, Goertsches R, Nos C, Castillo M, et al. Plasma osteopontin levels in multiple sclerosis. J Neuroimmunol 2005;158:231-9.

105. Vogt MH, Floris S, Killestein J, Knol DL, Smits M, et al. Osteopontin levels and increased disease activity in relapsing-remitting multiple sclerosis patients. J Neuroimmunol 2004;155:155-60. 
106. Wen SR, Liu GJ, Feng RN, Gong FC, Zhong H, et al. Increased levels of IL-23 and osteopontin in serum and cerebrospinal fluid of multiple sclerosis patients. J Neuroimmunol 2012;244:94-6.

107. Kivisäkk P, Healy BC, Francois K, Gandhi R, Gholipour T, et al. Evaluation of circulating osteopontin levels in an unselected cohort of patients with multiple sclerosis: relevance for biomarker development. Mult Scler 2014;20:438-44.

108. Braitch M, Nunan R, Niepel G, Edwards LJ, Constantinescu CS. Increased osteopontin levels in the cerebrospinal fluid of patients with multiple sclerosis. Arch Neurol 2008;65:633-5.

109. Vogt MH, ten Kate J, Drent RJ, Polman CH, Hupperts R. Increased osteopontin plasma levels in multiple sclerosis patients correlate with bone-specific markers. Mult Scler 2010;16:443-9.

110. Börnsen L, Khademi M, Olsson T, Sørensen PS, Sellebjerg F. Osteopontin concentrations are increased in cerebrospinal fluid during attacks of multiple sclerosis. Mult Scler 2011;17:32-42.

111. Szalardy L, Zadori D, Simu M, Bencsik K, Vecsei L, et al. Evaluating biomarkers of neuronal degeneration and neuroinflammation in CSF of patients with multiple sclerosis-osteopontin as a potential marker of clinical severity. J Neurol Sci 2013;331:38-42.

112. Dianzani C, Vecchio D, Clemente N, Chiocchetti A, Martinelli Boneschi F, et al. Untangling extracellular proteasome-osteopontin circuit dynamics in multiple sclerosis. Cells 2019;8:262.

113. Runia TF, van Meurs M, Nasserinejad K, Hintzen RQ. No evidence for an association of osteopontin plasma levels with disease activity in multiple sclerosis. Mult Scler 2014;20:1670-1.

114. Zhao Q, Cheng W, Xi Y, Cao Z, Xu Y, et al. IFN- $\beta$ regulates Th17 differentiation partly through the inhibition of osteopontin in experimental autoimmune encephalomyelitis. Mol Immunol 2018;93:20-30.

115. Hong J, Hutton GJ. Regulatory effects of interferon- $\beta$ on osteopontin and interleukin-17 expression in multiple sclerosis. J Interferon Cytokine Res 2010;30:751-7.

116. Iaffaldano P, Ruggieri M, Viterbo RG, Mastrapasqua M, Trojano M. The improvement of cognitive functions is associated with a decrease of plasma Osteopontin levels in Natalizumab treated relapsing multiple sclerosis. Brain Behav Immun 2014;35:176-81.

117. Mas A, Martínez A, de las Heras V, Bartolomé M, de la Concha EG, et al. The 795CT polymorphism in osteopontin gene is not associated with multiple sclerosis in a Spanish population. Mult Scler 2007;13:250-2.

118. Biernacka-Lukanty J, Michalowska-Wender G, Michalak S, Raczak B, Kozubski W, et al. Polymorphism of the osteopontin gene and clinical course of multiple sclerosis in the Polish population. Folia Neuropathol 2015;53:343-6.

119. Caillier S, Barcellos LF, Baranzini SE, Swerdlin A, Lincoln RR, et al; Multiple Sclerosis Genetics Group. Osteopontin polymorphisms and disease course in multiple sclerosis. Genes Immun 2003;4:312-5.

120. Chiocchetti A, Comi C, Indelicato M, Castelli L, Mesturini R, et al. Osteopontin gene haplotypes correlate with multiple sclerosis development and progression. J Neuroimmunol 2005;163:172-8.

121. Comi C, Cappellano G, Chiocchetti A, Orilieri E, Buttini S, et al. The impact of osteopontin gene variations on multiple sclerosis development and progression. Clin Dev Immunol 2012;2012:212893.

122. Londoño AC, Mora CA. Role of CXCL13 in the formation of the meningeal tertiary lymphoid organ in multiple sclerosis. F1000Res 2018;7:514.

123. Serafini B, Rosicarelli B, Magliozzi R, Stigliano E, Aloisi F. Detection of ectopic B-cell follicles with germinal centers in the meninges of patients with secondary progressive multiple sclerosis. Brain Pathol 2004;14:164-74.

124. Bagaeva LV, Rao P, Powers JM, Segal BM. CXC chemokine ligand 13 plays a role in experimental autoimmune encephalomyelitis. J Immunol 2006;176:7676-85.

125. Krumbholz M, Theil D, Cepok S, Hemmer B, Kivisäkk P, et al. Chemokines in multiple sclerosis: CXCL12 and CXCL13 up-regulation is differentially linked to CNS immune cell recruitment. Brain 2006;129:200-11.

126. Bai Z, Chen D, Wang L, Zhao Y, Liu T, et al. Cerebrospinal fluid and blood cytokines as biomarkers for multiple sclerosis: a systematic review and meta-analysis of 226 studies with 13,526 multiple sclerosis patients. Front Neurosci 2019;13:1026.

127. Sellebjerg F, Börnsen L, Khademi M, Krakauer M, Olsson T, et al. Increased cerebrospinal fluid concentrations of the chemokine CXCL13 in active MS. Neurology 2009;73:2003-10.

128. Khademi M, Kockum I, Andersson ML, Iacobaeus E, Brundin L, et al. Cerebrospinal fluid CXCL13 in multiple sclerosis: a suggestive prognostic marker for the disease course. Mult Scler 2011;17:335-43.

129. Irani DN. Regulated Production of CXCL13 within the Central Nervous System. J Clin Cell Immunol 2016;7:460.

130. Brettschneider J, Czerwoniak A, Senel M, Fang L, Kassubek J, et al. The chemokine CXCL13 is a prognostic marker in clinically isolated syndrome (CIS). PLoS One 2010;5:e11986.

131. Piccio L, Naismith RT, Trinkaus K, Klein RS, Parks BJ, et al. Changes in B- and T-lymphocyte and chemokine levels with rituximab treatment in multiple sclerosis. Arch Neurol 2010;67:707-14.

132. Romme Christensen J, Ratzer R, Börnsen L, Lyksborg M, Garde E, et al. Natalizumab in progressive MS: results of an open-label, phase 2A, proof-of-concept trial. Neurology 2014;82:1499-507.

133. Rempe RG, Hartz AMS, Bauer B. Matrix metalloproteinases in the brain and blood-brain barrier: Versatile breakers and makers. J Cereb Blood Flow Metab 2016;36:1481-507.

134. Wang Y, Wu H, Wu X, Bian Z, Gao Q. Interleukin 17A promotes gastric cancer invasiveness via NF-кB mediated matrix metalloproteinases 2 and 9 expression. PLoS One 2014;9:e96678.

135. Moon SK, Cha BY, Kim CH. ERK1/2 mediates TNF-alpha-induced matrix metalloproteinase-9 expression in human vascular smooth muscle cells via the regulation of NF-kappaB and AP-1: involvement of the ras dependent pathway. J Cell Physiol 2004;198:417-27.

136. Powell WC, Fingleton B, Wilson CL, Boothby M, Matrisian LM. The metalloproteinase matrilysin proteolytically generates active 
soluble Fas ligand and potentiates epithelial cell apoptosis. Current Biology 1999;9:1441-7.

137. Woo MS, Park JS, Choi IY, Kim WK, Kim HS. Inhibition of MMP-3 or -9 suppresses lipopolysaccharide-induced expression of proinflammatory cytokines and iNOS in microglia. J Neurochem 2008;106:770-80.

138. Agrawal S, Anderson P, Durbeej M, van Rooijen N, Ivars F, et al. Dystroglycan is selectively cleaved at the parenchymal basement membrane at sites of leukocyte extravasation in experimental autoimmune encephalomyelitis. J Exp Med 2006;203:1007-19.

139. Nygårdas PT, Hinkkanen AE. Up-regulation of MMP-8 and MMP-9 activity in the BALB/c mouse spinal cord correlates with the severity of experimental autoimmune encephalomyelitis. Clin Exp Immunol 2002;128:245-54.

140. Buhler LA, Samara R, Guzman E, Wilson CL, Krizanac-Bengez L, et al. Matrix metalloproteinase-7 facilitates immune access to the CNS in experimental autoimmune encephalomyelitis. BMC Neurosci 2009;10:17.

141. Fainardi E, Castellazzi M, Tamborino C, Trentini A, Manfrinato MC, et al. Potential relevance of cerebrospinal fluid and serum levels and intrathecal synthesis of active matrix metalloproteinase-2 (MMP-2) as markers of disease remission in patients with multiple sclerosis. Mult Scler 2009; 15:547-54.

142. Trentini A, Castellazzi M, Cervellati C, Manfrinato MC, Tamborino C, et al. Interplay between Matrix Metalloproteinase-9, Matrix Metalloproteinase-2, and Interleukins in Multiple Sclerosis Patients. Dis Markers 2016;2016:3672353.

143. Liuzzi GM, Trojano M, Fanelli M, Avolio C, Fasano A, et al. Intrathecal synthesis of matrix metalloproteinase-9 in patients with multiple sclerosis: implication for pathogenesis. Mult Scler 2002;8:222-8.

144. Lee MA, Palace J, Stabler G, Ford J, Gearing A, et al. Serum gelatinase B, TIMP-1 and TIMP-2 levels in multiple sclerosis. A longitudinal clinical and MRI study. Brain 1999;122:191-7.

145. Lichtinghagen R, Seifert T, Kracke A, Marckmann S, Wurster U, et al. Expression of matrix metalloproteinase-9 and its inhibitors in mononuclear blood cells of patients with multiple sclerosis. J Neuroimmunol 1999;99:19-26.

146. Waubant E, Goodkin DE, Gee L, Bacchetti P, Sloan R, et al. Serum MMP-9 and TIMP-1 levels are related to MRI activity in relapsing multiple sclerosis. Neurology 1999;53:1397-401.

147. Fainardi E, Castellazzi M, Bellini T, Manfrinato MC, Baldi E, et al. Cerebrospinal fluid and serum levels and intrathecal production of active matrix metalloproteinase-9 (MMP-9) as markers of disease activity in patients with multiple sclerosis. Mult Scler 2006;12:294-301.

148. Leppert D, Ford J, Stabler G, Grygar C, Lienert C, et al. Matrix metalloproteinase-9 (gelatinase B) is selectively elevated in CSF during relapses and stable phases of multiple sclerosis. Brain 1998;121:2327-34.

149. Benesová Y, Vasku A, Novotná H, Litzman J, Stourac P, et al. Matrix metalloproteinase-9 and matrix metalloproteinase-2 as biomarkers of various courses in multiple sclerosis. Mult Scler 2009;15:316-22.

150. Lindberg RL, De Groot CJ, Montagne L, Freitag P, van der Valk P, et al. The expression profile of matrix metalloproteinases (MMPs) and their inhibitors (TIMPs) in lesions and normal appearing white matter of multiple sclerosis. Brain 2001;124:1743-53.

151. Anthony DC, Ferguson B, Matyzak MK, Miller KM, Esiri MM, et al. Differential matrix metalloproteinase expression in cases of multiple sclerosis and stroke. Neuropathol Appl Neurobiol 1997;23:406-15.

152. Galboiz Y, Shapiro S, Lahat N, Rawashdeh H, Miller A. Matrix metalloproteinases and their tissue inhibitors as markers of disease subtype and response to interferon-beta therapy in relapsing and secondary-progressive multiple sclerosis patients. Ann Neurol 2001;50:443-51.

153. Bernal F, Elias B, Hartung HP, Kieseier BC. Regulation of matrix metalloproteinases and their inhibitors by interferon-beta: a longitudinal study in multiple sclerosis patients. Mult Scler 2009;15:721-7.

154. Comabella M, Río J, Espejo C, Ruiz de Villa M, Al-Zayat H, et al. Changes in matrix metalloproteinases and their inhibitors during interferon-beta treatment in multiple sclerosis. Clin Immunol 2009;130:145-50.

155. Balasa R, Bianca C, Septimiu V, Iunius S, Adina H, et al. The matrix metalloproteinases panel in multiple sclerosis patients treated with Natalizumab: a possible answer to Natalizumab non-responders. CNS Neurol Disord Drug Targets 2018;17:464-72.

156. Castellazzi M, Bellini T, Trentini A, Delbue S, Elia F, et al. Serum gelatinases levels in multiple sclerosis patients during 21 months of Natalizumab therapy. Dis Markers 2016;2016:8434209.

157. Fissolo N, Pignolet B, Matute-Blanch C, Triviño JC, Miró B, et al; Biomarkers and Response to Natalizumab for Multiple Sclerosis Treatment (BIONAT), Best EScalation Treatment in Multiple Sclerosis (BEST-MS), and the Société Francophone de la Sclérose En Plaques (SFSEP) Network. Matrix metalloproteinase 9 is decreased in natalizumab-treated multiple sclerosis patients at risk for progressive multifocal leukoencephalopathy. Ann Neurol 2017;82:186-95.

158. Cohen SR, Brooks BR, Herndon RM, McKhann GM. A diagnostic index of active demyelination: myelin basic protein in cerebrospinal fluid. Ann Neurol 1980;8:25-31.

159. Whitaker JN, Lisak RP, Bashir RM, Fitch OH, Seyer JM, et al. Immunoreactive myelin basic protein in the cerebrospinal fluid in neurological disorders. Ann Neurol 1980;7:58-64.

160. Stadelmann C, Timmler S, Barrantes-Freer A, Simons M. Myelin in the central nervous system: structure, function, and pathology. Physiol Rev 2019;99:1381-431.

161. Whitaker JN. Myelin basic protein in cerebrospinal fluid and other body fluids. Mult Scler 1998;4:16-21.

162. Meinl E, Hohlfeld R. Immunopathogenesis of multiple sclerosis: MBP and beyond. Clin Exp Immunol 2002;128:395-7.

163. Olsson T, Sun J, Hillert J, Höjeberg B, Ekre HP, et al. Increased numbers of T cells recognizing multiple myelin basic protein epitopes in multiple sclerosis. Eur J Immunol 1992;22:1083-7.

164. Kim YC, Zhang AH, Yoon J, Culp WE, Lees JR, et al. Engineered MBP-specific human Tregs ameliorate MOG-induced EAE through IL-2-triggered inhibition of effector T cells. J Autoimmun 2018;92:77-86.

165. Whitaker JN. Myelin encephalitogenic protein fragments in cerebrospinal fluid of persons with multiple sclerosis. Neurology 
1977;27:911-20

166. Sellebjerg F, Christiansen M, Nielsen PM, Frederiksen JL. Cerebrospinal fluid measures of disease activity in patients with multiple sclerosis. Mult Scler 1998;4:475-9.

167. Noppe M, Crols R, Andries D, Lowenthal A. Determination in human cerebrospinal fluid of glial fibrillary acidic protein, S-100 and myelin basic protein as indices of non-specific or specific central nervous tissue pathology. Clinica Chimica Acta 1986;155:143-50.

168. Lamers KJ, de Reus HP, Jongen PJ. Myelin basic protein in CSF as indicator of disease activity in multiple sclerosis. Mult Scler 1998;4:124-6.

169. Barkhof F, Frequin ST, Hommes OR, Lamers K, Scheltens P, et al. A correlative triad of gadolinium-DTPA MRI, EDSS, and CSF-MBP in relapsing multiple sclerosis patients treated with high-dose intravenous methylprednisolone. Neurology 1992;42:63-7.

170. Zhou Y, Simpson S Jr, Charlesworth JC, van der Mei I, Lucas RM, et al; AUSLONG Investigators Group. Variation within MBP gene predicts disease course in multiple sclerosis. Brain Behav 2017;7:e00670.

171. Belogurov A Jr, Zakharov K, Lomakin Y, Surkov K, Avtushenko S, et al. CD206-targeted liposomal myelin basic protein peptides in patients with multiple sclerosis resistant to first-line disease-modifying therapies: a first-in-human, proof-of-concept dose-escalation study. Neurotherapeutics 2016;13:895-904.

172. Warren KG, Catz I, Ferenczi LZ, Krantz MJ. Intravenous synthetic peptide MBP8298 delayed disease progression in an HLA Class IIdefined cohort of patients with progressive multiple sclerosis: results of a 24-month double-blind placebo-controlled clinical trial and 5 years of follow-up treatment. Eur J Neurol 2006;13:887-95.

173. Establish Tolerance In MS With Peptide-Coupled, Peripheral Blood Mononuclear Cells (ETIMS). Available from: https://clinicaltrials. gov/ct2/show/NCT01414634. [Last accessed on 7 Jul 2020]

174. Safety, Tolerability, and Effectiveness of CGP77116 in Patients With Multiple Sclerosis (MS). Available from: https:/clinicaltrials.gov/ ct2/show/NCT00001781. [Last accessed on 7 Jul 2020]

175. Tumani H, Hartung HP, Hemmer B, Teunissen C, Deisenhammer F, et al; BioMS Study Group. Cerebrospinal fluid biomarkers in multiple sclerosis. Neurobiol Dis 2009;35:117-27.

176. Zołtowska A, Stepiński J, Lewko B, Serkies K, Zamorska B, et al. Neural cell adhesion molecule in breast, colon and lung carcinomas. Arch Immunol Ther Exp (Warsz) 2001;49:171-4.

177. Massaro AR. The role of NCAM in remyelination. Neurol Sci 2002;22:429-35.

178. Massaro AR, Sbriccoli A, Tonali P. Reactive astrocytes within the acute plaques of multiple sclerosis are PSA-NCAM positive. Neurol Sci 2002;23:255-6.

179. Le Gal La Salle G, Rougon G, Valin A. The embryonic form of neural cell surface molecule (E-NCAM) in the rat hippocampus and its reexpression on glial cells following kainic acid- induced status epilepticus. J Neurosci 1992;12:872-82.

180. Gnanapavan S, Grant D, Illes-Toth E, Lakdawala N, Keir G, et al. Neural cell adhesion molecule--description of a CSF ELISA method and evidence of reduced levels in selected neurological disorders. J Neuroimmunol 2010;225:118-22.

181. Axelsson M, Dubuisson N, Novakova L, Malmeström C, Giovannoni G, et al. Cerebrospinal fluid NCAM levels are modulated by disease-modifying therapies. Acta Neurol Scand 2019;139:422-7.

182. Massaro AR, Albrechtsen M, Bock E. N-CAM in cerebrospinal fluid: a marker of synaptic remodelling after acute phases of multiple sclerosis? Ital J Neurol Sci 1987;Suppl 6:85-8.

183. Massaro AR. Are there indicators of remyelination in blood or CSF of multiple sclerosis patients? Mult Scler 1998;4:228-31.

184. Paul A, Comabella M, Gandhi R. Biomarkers in Multiple Sclerosis. Cold Spring Harb Perspect Med 2019;9:a029058.

185. Correale J, Fiol M. Chitinase effects on immune cell response in neuromyelitis optica and multiple sclerosis. Mult Scler 2011;17:521-31.

186. Kanneganti M, Kamba A, Mizoguchi E. Role of chitotriosidase (chitinase 1) under normal and disease conditions. J Epithel Biol Pharmacol 2012;5:1-9.

187. De Fino C, Lucchini M, Lucchetti D, Nociti V, Losavio FA, et al. The predictive value of CSF multiple assay in multiple sclerosis: a single center experience. Mult Scler Relat Disord 2019;35:176-81.

188. Novakova L, Axelsson M, Khademi M, Zetterberg H, Blennow K, et al. Cerebrospinal fluid biomarkers as a measure of disease activity and treatment efficacy in relapsing-remitting multiple sclerosis. J Neurochem 2017;141:296-304.

189. Sellebjerg F, Börnsen L, Ammitzbøll C, Nielsen JE, Vinther-Jensen T, et al. Defining active progressive multiple sclerosis. Mult Scler 2017;23:1727-35.

190. Comabella M, Fernández M, Martin R, Rivera-Vallvé S, Borrás E, et al. Cerebrospinal fluid chitinase 3-like 1 levels are associated with conversion to multiple sclerosis. Brain 2010;133:1082-93.

191. Borràs E, Cantó E, Choi M, Maria Villar L, Álvarez-Cermeño JC, et al. Protein-based classifier to predict conversion from clinically isolated syndrome to multiple sclerosis. Mol Cell Proteomics 2016;15:318-28.

192. Cantó E, Tintoré M, Villar LM, Costa C, Nurtdinov R, et al. Chitinase 3-like 1: prognostic biomarker in clinically isolated syndromes. Brain 2015;138:918-31.

193. Matute-Blanch C, Río J, Villar LM, Midaglia L, Malhotra S, et al. Chitinase 3-like 1 is associated with the response to interferon-beta treatment in multiple sclerosis. J Neuroimmunol 2017;303:62-5.

194. Lovett-Racke AE, Yang Y, Racke MK. Th1 versus Th17: are T cell cytokines relevant in multiple sclerosis? Biochim Biophys Acta 2011;1812:246-51.

195. Longbrake EE, Racke MK. Why did IL-12/IL-23 antibody therapy fail in multiple sclerosis? Expert Rev Neurother 2009;9:319-21.

196. Cua DJ, Sherlock J, Chen Y, Murphy CA, Joyce B, et al. Interleukin-23 rather than interleukin-12 is the critical cytokine for autoimmune inflammation of the brain. Nature 2003;421:744-8. 
197. Segal BM, Constantinescu CS, Raychaudhuri A, Kim L, Fidelus-gort R, et al. Repeated subcutaneous injections of IL12/23 p40 neutralising antibody, ustekinumab, in patients with relapsing-remitting multiple sclerosis: a phase II, double-blind, placebo-controlled, randomised, dose-ranging study. Lancet Neurol 2008;7:796-804.

198. Matusevicius D, Kivisäkk P, He B, Kostulas N, Ozenci V, et al. Interleukin-17 mRNA expression in blood and CSF mononuclear cells is augmented in multiple sclerosis. Mult Scler 1999;5:101-4.

199. Lock C, Hermans G, Pedotti R, Brendolan A, Schadt E, et al. Gene-microarray analysis of multiple sclerosis lesions yields new targets validated in autoimmune encephalomyelitis. Nat Med 2002;8:500-8.

200. Brucklacher-Waldert V, Stuerner K, Kolster M, Wolthausen J, Tolosa E. Phenotypical and functional characterization of T helper 17 cells in multiple sclerosis. Brain 2009;132:3329-41.

201. Havrdová E, Belova A, Goloborodko A, Tisserant A, Wright A, et al. Activity of secukinumab, an anti-IL-17A antibody, on brain lesions in RRMS: results from a randomized, proof-of-concept study. J Neurol 2016;263:1287-95.

202. Ishizu T, Osoegawa M, Mei FJ, Kikuchi H, Tanaka M, et al. Intrathecal activation of the IL-17/IL-8 axis in opticospinal multiple sclerosis. Brain 2005;128:988-1002.

203. Rossi S, Motta C, Studer V, Barbieri F, Buttari F, et al. Tumor necrosis factor is elevated in progressive multiple sclerosis and causes excitotoxic neurodegeneration. Mult Scler 2014;20:304-12.

204. Trenova AG, Slavov GS, Draganova-Filipova MN, Mateva NG, Manova MG, et al. Circulating levels of interleukin-17A, tumor necrosis factor-alpha, interleukin-18, interleukin-10, and cognitive performance of patients with relapsing-remitting multiple sclerosis. Neurol Res 2018;40:153-9.

205. Pegoretti V, Baron W, Laman JD, Eisel ULM. Selective Modulation of TNF-TNFRs Signaling: insights for multiple sclerosis treatment. Front Immunol 2018;9:925.

206. Caminero A, Comabella M, Montalban X. Tumor necrosis factor alpha (TNF- $\alpha$ ), anti-TNF- $\alpha$ and demyelination revisited: an ongoing story. J Neuroimmunol 2011;234:1-6.

207. Brambilla R, Ashbaugh JJ, Magliozzi R, Dellarole A, Karmally S, et al. Inhibition of soluble tumour necrosis factor is therapeutic in experimental autoimmune encephalomyelitis and promotes axon preservation and remyelination. Brain 2011;134:2736-54.

208. Ng LG, Sutherland AP, Newton R, Qian F, Cachero TG, et al. B cell-activating factor belonging to the TNF family (BAFF)-R is the principal BAFF receptor facilitating BAFF costimulation of circulating T and B cells. J Immunol 2004;173:807-17.

209. Kannel K, Alnek K, Vahter L, Gross-Paju K, Uibo R, et al. Changes in blood B cell-activating factor (BAFF) levels in multiple sclerosis: a sign of treatment outcome. PLoS One 2015;10:e0143393.

210. Friede RL, Samorajski T. Axon caliber related to neurofilaments and microtubules in sciatic nerve fibers of rats and mice. Anat Rec 1970;167:379-87.

211. Varhaug KN, Torkildsen Ø, Myhr KM, Vedeler CA. Neurofilament light chain as a biomarker in multiple sclerosis. Front Neurol 2019;10:338.

212. Rosengren LE, Karlsson JE, Karlsson JO, Persson LI, Wikkelsø C. Patients with amyotrophic lateral sclerosis and other neurodegenerative diseases have increased levels of neurofilament protein in CSF. J Neurochem 1996;67:2013-8.

213. De Schaepdryver M, Jeromin A, Gille B, Claeys KG, Herbst V, et al. Comparison of elevated phosphorylated neurofilament heavy chains in serum and cerebrospinal fluid of patients with amyotrophic lateral sclerosis. J Neurol Neurosurg Psychiatry 2018;89:367-73.

214. Fyfe I. Alzheimer disease: neurofilament light in the blood marks Alzheimer degeneration. Nat Rev Neurol 2017;13:257.

215. Meeter LH, Dopper EG, Jiskoot LC, Sanchez-Valle R, Graff C, et al. Neurofilament light chain: a biomarker for genetic frontotemporal dementia. Ann Clin Transl Neurol 2016;3:623-36.

216. Mages B, Aleithe S, Altmann S, Blietz A, Nitzsche B, et al. Impaired neurofilament integrity and neuronal morphology in different models of focal cerebral ischemia and human stroke tissue. Front Cell Neurosci 2018;12:161.

217. Byrne LM, Rodrigues FB, Blennow K, Durr A, Leavitt BR, et al. Neurofilament light protein in blood as a potential biomarker of neurodegeneration in Huntington's disease: a retrospective cohort analysis. Lancet Neurol 2017;16:601-9.

218. Bridel C, van Wieringen WN, Zetterberg H, Tijms BM, Teunissen CE, et al; and the NFL Group. Diagnostic value of cerebrospinal fluid neurofilament light protein in neurology: a systematic review and meta-analysis. JAMA Neurol 2019;76:1035-48.

219. Bergman J, Dring A, Zetterberg H, Blennow K, Norgren N, et al. Neurofilament light in CSF and serum is a sensitive marker for axonal white matter injury in MS. Neurol Neuroimmunol Neuroinflamm 2016;3:e271.

220. Novakova L, Zetterberg H, Sundström P, Axelsson M, Khademi M, et al. Monitoring disease activity in multiple sclerosis using serum neurofilament light protein. Neurology 2017;89:2230-7.

221. Kuhle J, Barro C, Disanto G, Mathias A, Soneson C, et al. Serum neurofilament light chain in early relapsing remitting MS is increased and correlates with CSF levels and with MRI measures of disease severity. Mult Scler 2016;22:1550-9.

222. Kuhle J, Barro C, Andreasson U, Derfuss T, Lindberg R, et al. Comparison of three analytical platforms for quantification of the neurofilament light chain in blood samples: ELISA, electrochemiluminescence immunoassay and Simoa. Clin Chem Lab Med 2016;54:1655-61.

223. Disanto G, Barro C, Benkert P, Naegelin Y, Schädelin S, et al; Swiss Multiple Sclerosis Cohort Study Group. Serum neurofilament light: a biomarker of neuronal damage in multiple sclerosis. Ann Neurol 2017;81:857-70.

224. Teunissen CE, Iacobaeus E, Khademi M, Brundin L, Norgren N, et al. Combination of CSF N-acetylaspartate and neurofilaments in multiple sclerosis. Neurology 2009;72:1322-9.

225. Kuhle J, Leppert D, Petzold A, Regeniter A, Schindler C, et al. Neurofilament heavy chain in CSF correlates with relapses and disability in multiple sclerosis. Neurology 2011;76:1206-13. 
226. Norgren N, Sundström P, Svenningsson A, Rosengren L, Stigbrand T, et al. Neurofilament and glial fibrillary acidic protein in multiple sclerosis. Neurology 2004;63:1586-90.

227. Cai L, Huang J. Neurofilament light chain as a biological marker for multiple sclerosis: a meta-analysis study. Neuropsychiatr Dis Treat 2018;14:2241-54.

228. Martin SJ, McGlasson S, Hunt D, Overell J. Cerebrospinal fluid neurofilament light chain in multiple sclerosis and its subtypes: a metaanalysis of case-control studies. J Neurol Neurosurg Psychiatry 2019;90:1059-67.

229. Kuhle J, Nourbakhsh B, Grant D, Morant S, Barro C, et al. Serum neurofilament is associated with progression of brain atrophy and disability in early MS. Neurology 2017;88:826-31.

230. Quintana E, Coll C, Salavedra-Pont J, Muñoz-San Martín M, Robles-Cedeño R, et al. Cognitive impairment in early stages of multiple sclerosis is associated with high cerebrospinal fluid levels of chitinase 3-like 1 and neurofilament light chain. Eur J Neurol 2018;25:1189-91.

231. Kuhle J, Plavina T, Barro C, Disanto G, Sangurdekar D, et al. Neurofilament light levels are associated with long-term outcomes in multiple sclerosis. Mult Scler 2019; doi: 10.1177/1352458519885613.

232. Ferraro D, Guicciardi C, De Biasi S, Pinti M, Bedin R, et al. Plasma neurofilaments correlate with disability in progressive multiple sclerosis patients. Acta Neurol Scand 2020;141:16-21.

233. Disanto G, Adiutori R, Dobson R, Martinelli V, Dalla Costa G, et al; International Clinically Isolated Syndrome Study Group. Serum neurofilament light chain levels are increased in patients with a clinically isolated syndrome. J Neurol Neurosurg Psychiatry 2016;87:126-9.

234. Martínez MA, Olsson B, Bau L, Matas E, Cobo Calvo Á, et al. Glial and neuronal markers in cerebrospinal fluid predict progression in multiple sclerosis. Mult Scler 2015;21:550-61.

235. Modvig S, Degn M, Roed H, Sørensen TL, Larsson HB, et al. Cerebrospinal fluid levels of chitinase 3-like 1 and neurofilament light chain predict multiple sclerosis development and disability after optic neuritis. Mult Scler 2015;21:1761-70.

236. Siller N, Kuhle J, Muthuraman M, Barro C, Uphaus T, et al. Serum neurofilament light chain is a biomarker of acute and chronic neuronal damage in early multiple sclerosis. Mult Scler 2019;25:678-86.

237. Varhaug KN, Barro C, Bjørnevik K, Myhr KM, Torkildsen Ø, et al. Neurofilament light chain predicts disease activity in relapsingremitting MS. Neurol Neuroimmunol Neuroinflamm 2018;5:e422.

238. Chitnis T, Gonzalez C, Healy BC, Saxena S, Rosso M, et al. Neurofilament light chain serum levels correlate with 10-year MRI outcomes in multiple sclerosis. Ann Clin Transl Neurol 2018;5:1478-91.

239. Axelsson M, Malmeström C, Gunnarsson M, Zetterberg H, Sundström P, et al. Immunosuppressive therapy reduces axonal damage in progressive multiple sclerosis. Mult Scler 2014;20:43-50.

240. Novakova L, Axelsson M, Khademi M, Zetterberg H, Blennow K, et al. Cerebrospinal fluid biomarkers of inflammation and degeneration as measures of fingolimod efficacy in multiple sclerosis. Mult Scler 2017;23:62-71.

241. Kuhle J, Malmeström C, Axelsson M, Plattner K, Yaldizli O, et al. Neurofilament light and heavy subunits compared as therapeutic biomarkers in multiple sclerosis. Acta Neurol Scand 2013;128:e33-6.

242. Gunnarsson M, Malmeström C, Axelsson M, Sundström P, Dahle C, et al. Axonal damage in relapsing multiple sclerosis is markedly reduced by natalizumab. Ann Neurol 2011;69:83-9.

243. Akgün K, Kretschmann N, Haase R, Proschmann U, Kitzler HH, et al. Profiling individual clinical responses by high-frequency serum neurofilament assessment in MS. Neurol Neuroimmunol Neuroinflamm 2019;6:e555.

244. Traditional Versus Early Aggressive Therapy for Multiple Sclerosis Trial (TREAT-MS). Available from: https://clinicaltrials.gov/ct2/ show/NCT03500328. [Last accessed on 9 Jul 2020]

245. Janeway CA Jr, Travers P, Walport M, Shlomchik MJ. Immunobiology: the immune system in health and disease. 5th edition. New York: Garland Science; 2001. Available from: https:/www.ncbi.nlm.nih.gov/books/NBK27162/. [Last accessed on 9 Jul 2020]

246. Sharief MK, Keir G, Thompson EJ. Intrathecal synthesis of IgM in neurological diseases: a comparison between detection of oligoclonal bands and quantitative estimation. J Neurol Sci 1990;96:131-42.

247. Villar LM, Masjuan J, González-Porqué P, Plaza J, Sádaba MC, et al. Intrathecal IgM synthesis is a prognostic factor in multiple sclerosis. Ann Neurol 2003;53:222-6.

248. Mandrioli J, Sola P, Bedin R, Gambini M, Merelli E. A multifactorial prognostic index in multiple sclerosis. Cerebrospinal fluid IgM oligoclonal bands and clinical features to predict the evolution of the disease. J Neurol 2008;255:1023-31.

249. Magraner MJ, Bosca I, Simó-Castelló M, García-Martí G, Alberich-Bayarri A, et al. Brain atrophy and lesion load are related to CSF lipid-specific IgM oligoclonal bands in clinically isolated syndromes. Neuroradiology 2012;54:5-12.

250. Villar LM, Sádaba MC, Roldán E, Masjuan J, González-Porqué P, et al. Intrathecal synthesis of oligoclonal IgM against myelin lipids predicts an aggressive disease course in MS. J Clin Invest 2005;115:187-94.

251. Durante L, Zaaraoui W, Rico A, Crespy L, Wybrecht D, et al. Intrathecal synthesis of IgM measured after a first demyelinating event suggestive of multiple sclerosis is associated with subsequent MRI brain lesion accrual. Mult Scler 2012;18:587-91.

252. Boscá I, Magraner MJ, Coret F, Alvarez-Cermeño JC, Simó-Castelló M, et al. The risk of relapse after a clinically isolated syndrome is related to the pattern of oligoclonal bands. J Neuroimmunol 2010;226:143-6.

253. Ferraro D, Simone AM, Bedin R, Galli V, Vitetta F, et al. Cerebrospinal fluid oligoclonal IgM bands predict early conversion to clinically definite multiple sclerosis in patients with clinically isolated syndrome. J Neuroimmunol 2013;257:76-81.

254. Espiño M, Abraira V, Arroyo R, Bau L, Cámara C, et al. Assessment of the reproducibility of oligoclonal IgM band detection for its application in daily clinical practice. Clin Chim Acta 2015;438:67-9. 
255. Sola P, Mandrioli J, Simone AM, Ferraro D, Bedin R, et al. Primary progressive versus relapsing-onset multiple sclerosis: presence and prognostic value of cerebrospinal fluid oligoclonal IgM. Mult Scler 2011;17:303-11.

256. Bosca I, Villar LM, Coret F, Magraner MJ, Simó-Castelló M, et al. Response to interferon in multiple sclerosis is related to lipid-specific oligoclonal IgM bands. Mult Scler 2010;16:810-5.

257. Selter RC, Biberacher V, Grummel V, Buck D, Eienbröker C, et al. Natalizumab treatment decreases serum IgM and IgG levels in multiple sclerosis patients. Mult Scler 2013;19:1454-61.

258. Villar LM, García-Sánchez MI, Costa-Frossard L, Espiño M, Roldán E, et al. Immunological markers of optimal response to natalizumab in multiple sclerosis. Arch Neurol 2012;69:191-7.

259. Hol EM, Pekny M. Glial fibrillary acidic protein (GFAP) and the astrocyte intermediate filament system in diseases of the central nervous system. Curr Opin Cell Biol 2015;32:121-30.

260. Bélanger M, Magistretti PJ. The role of astroglia in neuroprotection. Dialogues Clin Neurosci 2009;11:281-95.

261. Yang Z, Wang KK. Glial fibrillary acidic protein: from intermediate filament assembly and gliosis to neurobiomarker. Trends Neurosci 2015;38:364-74

262. Liddelow SA, Guttenplan KA, Clarke LE, Bennett FC, Bohlen CJ, et al. Neurotoxic reactive astrocytes are induced by activated microglia. Nature 2017;541:481-7.

263. Mahad DH, Trapp BD, Lassmann H. Pathological mechanisms in progressive multiple sclerosis. Lancet Neurol 2015;14:183-93.

264. Abdelhak A, Hottenrott T, Morenas-Rodríguez E, Suárez-Calvet M, Zettl UK, et al. Glial activation markers in CSF and serum from patients with primary progressive multiple sclerosis: potential of serum GFAP as disease severity marker? Front Neurol 2019;10:280.

265. Rosengren L, Lycke J, Andersen O. Glial fibrillary acidic protein in CSF of multiple sclerosis patients: relation to neurological deficit. J Neurol Sci 1995;133:61-5.

266. Petzold A, Eikelenboom MJ, Gveric D, Keir G, Chapman M, et al. Markers for different glial cell responses in multiple sclerosis: clinical and pathological correlations. Brain 2002;125:1462-73.

267. Axelsson M, Malmeström C, Nilsson S, Haghighi S, Rosengren L, et al. Glial fibrillary acidic protein: a potential biomarker for progression in multiple sclerosis. J Neurol 2011;258:882-8.

268. Högel H, Rissanen E, Barro C, Matilainen M, Nylund M, et al. Serum glial fibrillary acidic protein correlates with multiple sclerosis disease severity. Mult Scler 2020;26:210-9.

269. Kassubek R, Gorges M, Schocke M, Hagenston VAM, Huss A, et al. GFAP in early multiple sclerosis: A biomarker for inflammation. Neurosci Lett 2017;657:166-70. 